\title{
Finite Element Model for Piles in Liquefiable Ground
}

\author{
by, Rui Wang ${ }^{1}$, Pengcheng $\mathrm{Fu}^{2}$ and Jian-Min Zhang ${ }^{1}{ }^{*}$
}

\begin{abstract}
This paper develops a three dimensional finite element modelling method for piles in liquefiable ground and applies it to the analysis of seismic pile responses. A unified plasticity model for large post-liquefaction shear deformation of sand provides the basis for the effective and efficient modelling of liquefiable ground. Special attention is dedicated towards the modelling of piles and soil-pile interface to accurately reflect the behaviour of piles. A staged modelling procedure is adopted to appropriately generate the initial conditions for the soil and piles and achieve hydrostatic pore pressure prior to seismic loading. Three centrifuge shaking table tests on single piles, both with and without pile cap and superstructure, in level and inclined liquefiable ground are conducted and simulated in validation and application of the proposed method. Further studies to investigate the effects of pile cap, lateral spreading, and non-liquefiable surface layer are undertaken numerically using the validated method. The results show these aforementioned factors to be influential in the dynamic and residual response of piles in liquefiable ground.
\end{abstract}

Keywords: Seismic pile response; Liquefaction; Constitutive model; FEM; Centrifuge test.

\footnotetext{
${ }^{1}$ School of Civil Engineering/State Key Laboratory of Hydroscience and Engineering, Department of Hydraulic Engineering, Tsinghua University, Beijing, 100084, China.

* Corresponding author: zhangjm@mail.tsinghua.edu.cn

2 Atmospheric, Earth, and Energy Division, Lawrence Livermore National Laboratory, Livermore, CA 94550, USA
} 


\section{Introduction}

Since the mass occurrences of pile foundation failures in the 1964 Alaska and the 1964 Niigata earthquakes [1,2], damage to pile foundations in liquefiable ground have been observed in numerous strong earthquakes (e.g. [3-7]). It is well recognized that the analysis of the seismic response of piles in liquefiable ground is an extremely important and, due to its intrinsic complexity, challenging subject in geotechnical earthquake engineering. Such analyses have evolved from simple static methods to more sophisticated high fidelity numerical simulations.

A variety of pseudo-static analysis methods have been proposed and adopted by design guidelines and codes for assessing the behaviour of piles in liquefiable ground. The Japanese Road Association (JRA) [8] and Dobry et al. [9] suggested force-based methods that treat liquefied soil layers as a limit lateral pressure acting on piles. Many other studies have adopted displacement-based approaches in the form of a static "beam on nonlinear Winkler foundation (BNWF)" or the "p-y" method, where soil resistance is reflected through a series of nonlinear springs attached to the pile. After introducing the nonlinear p-y method for laterally loaded piles [10, 11], Matlock [12], Reese et al. [13], API [14], and others established p-y curves for clays and sands that have been widely adopted. Subsequently, the p-y method was extended to liquefiable soils by applying a "p multiplier" $[15,16]$, or by developing p-y curves for liquefied sand [17]. Combining the force- and displacement-based methods, Cubrinovski et al. [18] proposed to use limit pressures for non-liquefied crust layers and linear springs with a "stiffness degradation factor" for liquefied layers during liquefaction-induced lateral 
spreading. While the aforementioned pseudo-static methods are able to reflect the basic force-displacement relationship of soil-pile interaction and can be performed with ease, they are incapable of capturing the dynamically evolving soil properties and their effects on soil-pile interaction during earthquakes. Pseudo-static methods also suffer difficulties in appropriately combining inertial and kinematic loads (e.g. [19-21]).

Dynamic analysis is not limited by many of the empirical assumptions of pseudostatic methods, and can reflect the progressive changes in soil-pile interaction in liquefiable ground. Based on a dynamic $p-y$ element developed by Boulanger et al. [22] that incorporated elastic, plastic, damping and gap components, Brandenberg et al. [23] associated the capacity of the p-y material linearly with the effective stress in the freefield for the degradation of p-y behaviour due to liquefaction. Liyanapathirana and Poulos [19] used a degraded soil stiffness in their p-y formulation to take liquefaction into consideration. These methods utilize the ground motion and effective stress obtained from free-field site response analysis, but cannot accurately consider nearfield properties. Varun [24] proposed a semi-empirical method of generating near-field pore pressure from free-field values and plastic work in the p-y element, which to some extent incorporates the effect of near-field soil. Although dynamic p-y methods provide a useful means to reflect the interaction between pile and free-field soil in liquefiable ground, they over-simplify the dynamic response of soil and the approximation of the material properties tend to be rather crude.

Three-dimensional (3D) dynamic continuum methods can model soil-pile interaction in liquefiable ground with a high fidelity by properly taking into account the 
effects of kinematic and inertial interactions, the effects of pore water pressures, and nonlinear constitutive behaviour of soil [25]. Finn and Fujita [26] proposed a 3D finite element model that used an equivalent linear constitutive model for soil and beam elements which were connected directly to the soil elements for piles. However, Wotherspoon [27] and Sanchez and Roesset [28] reported that because beam elements do not reflect the geometrical cross section of the pile, such approach tends to underestimate the stiffness of the pile. As an improvement, Cheng and Jeremic [29] and Lu et al. [30] created a void in the finite element mesh to represent the pile geometry, and connected the pile beam-column elements with surrounding soil elements using rigid beam-column links, aiming at physically representing the pile cross section. Fully 3D models representing piles with solid elements can be used with appropriate element types and meshing accounting for bending of the pile [31], thereby providing a more realistic physical representation of the soil-pile system.

Soil constitutive model is a crucial component in these dynamic continuum simulation methods and should adequately reflect physical processes including plasticity, dilatancy, cyclic mobility, and especially post-liquefaction deformation. Various constitutive models been developed to capture the cyclic mobility and liquefaction features of sands. Widely used models include the UBCSAND models (e.g. $[32,33]$ ), generalized plasticity models (e.g. [34, 35), multi-surface models (e.g. [36, 37]), and bounding surface plasticity models (e.g. [38-42]). In the 3D dynamic finite element simulations described above, Cheng and Jeremic [29] used the DafaliasManzari [40] model and Lu et al. [30] used a multi-yield surface plasticity model [37] 
for sand. Although each of these models has its own unique features and advantages, most fell short of providing adequate description of the post-liquefaction behaviour of sand [43].

This paper presents a three dimensional finite element analysis method and applies it on modelling the seismic response of piles in liquefiable ground. A novel plasticity model developed by Wang et al. [43] combined with u-p solid-fluid coupled element formulation is used to simulate the soil medium, which is concisely presented in Section 2. In Section 3, special attention is paid to modelling of piles to accurately reflect the bending of piles and soil-pile interaction. Section 4 presents the staged modelling procedure for generating realistic initial conditions prior to seismic loading. Three centrifuge shaking table tests containing single piles and their finite element simulation setup are described in Section 5. The proposed method is validated against test results in Section 6, and then further applied in a preliminary investigation of the effects of pile cap, lateral spreading, and non-liquefiable surface layer in Section 7.

\section{Sand model}

\section{Constitutive formulation}

Aside from being able to reflect the basic elastic-plastic behaviour, the constitutive model used for liquefiable sand surrounding piles is desired to : (1) reflect the cyclic mobility of sand; (2) capture the generation and accumulation of shear strains at liquefaction as observed in laboratory tests (e.g. [44-46]); and (3) account for the behaviour of sand at various densities and confining stress, as the density and confining stress is expected to change during shaking, especially near the piles. To this end, a 
unified plasticity model for large post-liquefaction shear deformation of sand [43] was developed within the bounding surface plasticity framework [47]. The constitutive model incorporates a physics-based formulation for post-liquefaction shear deformation and directly links cyclic mobility with dilatancy through a unique decomposition of volumetric strains, while in compliance with critical state soil mechanics concepts. These formulations enable a unified description for pre- to postliquefaction stages under monotonic and cyclic loading.

Key features related to dilatancy and post-liquefaction deformation in the model are briefly discussed here, while a more detailed description of the model can be found in Wang et al. [43]. The model introduced a unique decomposition of volumetric strain $\varepsilon_{v}:$

$$
\varepsilon_{v}=\varepsilon_{v c}+\varepsilon_{v d, i r}+\varepsilon_{v d, r e}
$$

where $\varepsilon_{v c}$ is induced by mean effective stress change, $\varepsilon_{v d, r e}$ is induced by reversible dilatancy, and $\varepsilon_{v d, i r}$ caused by irreversible dilatancy. This scheme was proposed by Shamoto et al. [48] and Zhang [49] based on observations from draine cyclic torsional tests on sand, and directly connects cyclic mobility with dilatancy.

Based on this decomposition, post-liquefaction shear deformation can then be generated at liquefaction. $\varepsilon_{v c}$ has a unique dependency on the effective confining stress at any non-zero stress states, and a threshold value $\varepsilon_{v c, 0}$ exists for which zero effective stress is reached. Once zero effective stress state (i.e. liquefaction) is reached, $\varepsilon_{v c}$ would then be determined by volumetric compatibility in Eq. (1). For sand to leave the liquefaction state where $\varepsilon_{v c}$ exceeds $\varepsilon_{v c, 0}$, a corresponding amount of dilatancy 
induced volumetric strain is needed, which requires sufficient plastic shear strain $\varepsilon_{q}^{p}$ according to dilatancy relations, causing post-liquefaction shear deformation as:

$$
\varepsilon_{v d, i r}+\varepsilon_{v d, r e}=\int D\left|d \varepsilon_{q}^{p}\right|
$$

Similar to the decomposition of volumetric strain, dilatancy rate $D$ is also decomposed into a reversible part $D_{r e}$ and an irreversible part $D_{i r}$ :

$$
D=\frac{\dot{\varepsilon}_{v}^{p}}{\left|\dot{\varepsilon}_{q}^{p}\right|}=D_{r e}+D_{i r}
$$

where the dilatancy rates are formulated based on experimental observations. Although formulated rather differently, the decomposition of dilatancy in the current model holds a similar notion to the fabric dilatancy tensor described by Dafalias and Manzari (2004) [40] in terms of correctly reflecting the development of dilatancy after load reversal, hence reproducing the cyclic mobility of sand. The reversible and irreversible dilatancy concept in the proposed model allows for the development of post-liquefaction shear strain with increasing load cycles.

The model complies with critical state soil mechanics to provide a unified description of sand at various state, and has been validated against a wide range of monotonic/cyclic drained/undrained laboratory tests and has shown great capabilities in providing unified description of sand behaviour under the considered conditions [43]. Fig. 1 shows a simulation of undrained cyclic torsional test on Nevada sand conducted by Kutter et al (1994) [44], highlighting its capability in reproducing the cyclic mobility and post-liquefaction shear deformation of sand. The model's accurate description of cyclic mobility is important in reflecting the stiffness degradation for soil-pile interaction, and its unique generation of post-liquefaction shear deformation offers 
significant advantage in simulating piles in liquefied sand.

Numerical application with symmetrisation

Stress integration of the constitutive model is achieved through a cutting plane algorithm [51] with sub-stepping, which was described in detail by Wang et al. [43]. Due to the computation demand of the plasticity model, methods to speedup computation are highly desirable in its numerical application.

The continuum tangent operator is used in the solution of the global finite element equations according to the semi-explicit nature of the stress integration scheme:

$$
\begin{gathered}
\Delta \boldsymbol{\sigma}=\mathbf{D}_{\mathrm{ep}}: \Delta \boldsymbol{\varepsilon} \\
\mathbf{D}_{\mathrm{ep}}=\mathbf{D}_{\mathrm{e}}-\frac{\mathbf{D}_{\mathrm{e}}:\left(\mathbf{m}+\frac{D}{3} \mathbf{I}\right) \otimes\left(\mathbf{n}-\frac{1}{3}(\mathbf{r}: \mathbf{n}) \mathbf{I}\right): \mathbf{D}_{\mathbf{e}}}{H+\left(\mathbf{n}-\frac{1}{3}(\mathbf{r}: \mathbf{n}) \mathbf{I}\right): \mathbf{D}_{\mathrm{e}}:\left(\mathbf{m}+\frac{D}{3} \mathbf{I}\right)}
\end{gathered}
$$

where $\boldsymbol{\sigma}$ is the effective stress tensor, $\boldsymbol{\varepsilon}$ is the strain tensor, $\mathbf{D}_{\mathbf{e}}$ and $\mathbf{D}_{\mathrm{ep}}$ are the elastic and elastic-plastic tangent operators, $H$ is the plastic modulus, unit vector m represents the deviatoric strain flow direction, $\mathbf{n}$ is a unit deviatoric tensor serving as the loading direction in deviatoric stress space, $\mathbf{I}$ is the second rank identity tensor, ":" denotes the trace of the product of adjacent tensors, and " $\otimes$ " denotes the tensor product. As is seen in Eq. (5) the tangent operator is not symmetric due to the non-associated flow rule, resulting in an asymmetric system of equations, which is undesirable due to the high computational cost. Various methods that symmetrise nonassociated constitutive models have been developed (e.g. [52-54]). In our implementation, the tangent matrix transformation technique developed by Xiong [53] was adopted, and is expressed as: 


$$
\mathbf{D}_{\mathrm{ep}}=\mathbf{D}_{\mathrm{e}}-\frac{\mathbf{D}_{\mathrm{e}}:\left(\mathbf{m}+\frac{D}{3} \mathbf{I}\right) \otimes\left(\mathbf{m}+\frac{D}{3} \mathbf{I}\right): \mathbf{D}_{\mathbf{e}}}{H+\left(\mathbf{n}-\frac{1}{3}(\mathbf{r}: \mathbf{n}) \mathbf{I}\right): \mathbf{D}_{\mathrm{e}}:\left(\mathbf{m}+\frac{D}{3} \mathbf{I}\right)} \cdot \frac{\left(\mathbf{n}-\frac{1}{3}(\mathbf{r}: \mathbf{n}) \mathbf{I}\right): \mathbf{D}_{\mathrm{e}}: \Delta \boldsymbol{\varepsilon}}{\left(\mathbf{m}+\frac{D}{3} \mathbf{I}\right): \mathbf{D}_{\mathbf{e}}: \Delta \boldsymbol{\varepsilon}}
$$

For the models of piles in liquefiable ground studied in this paper, this symmetrisation technique reduces computation time by $35 \%$ on average.

The numerical implementation of the constitutive model has been made available in the open source finite element framework OpenSees [55]. OpenSees's u-p brick element [56] is adopted for solid-fluid coupling in the effective stress analysis of saturated sand. The capability of the $u-p$ formulation in capturing dynamic pore pressure was validated by Zienkiewicz et al. $[57,58]$ and is considered appropriate for soils with the coefficient of permeability smaller than $10^{-3} \mathrm{~m} / \mathrm{s}$ in the complete loading frequency range, and acceptable for loading frequencies greater than $2 \mathrm{~Hz}$ when the coefficient of permeability is less than $10^{-1} \mathrm{~m} / \mathrm{s}$, which meets the requirements of this study, where the coefficient of permeability is in the range of $10^{-5} \sim 10^{-4} \mathrm{~m} / \mathrm{s}$.

\section{Pile and interface models}

Second order twenty-node brick elements are used for the piles to provide an appropriate physical representation of the soil-pile system. The cross section of a pile consists of a number of elements along the bending direction (Fig. 2), intended to fully capture the bending of the pile. The moment on the pile is calculated by summing the product of the average stress on each relevant element $\left(\sigma_{\text {ave }, i}\right)$ with its area $\left(A_{i}\right)$ and moment $\operatorname{arm}\left(l_{i}\right)$ :

$$
M=\sum \sigma_{a v e, i} A_{i} l_{i}
$$

To prove that the finite element representation of the pile can accurately capture the 
bending deformation, we simulate a pile alone as a cantilever bending column in Fig. 3. The deflection and bending moments solved by the finite element model with six second-order hexahedron elements along the bending direction show excellent agreement with the corresponding closed-form solutions of Euler beam theory.

A hyperbolic model [59] is used for the soil-pile interface, in which the shear modulus is determined as:

$$
G_{t}=G_{0 c} P_{a}\left(\frac{\sigma_{n}}{P_{a}}\right)^{n}\left(1-R_{f} \frac{\tau}{\sigma_{n} \tan \phi}\right)^{2}
$$

where $G_{0 c}, n, R_{f}$ and $\phi$ are model parameters, $P_{a}$ is the atmospheric pressure, and $\sigma_{n}$ and $\tau$ are the normal and tangential stresses at the interface, respectively. For the simulations in this paper, the normal direction of the interface is the direction perpendicular to the associated pile surface.

\section{Staged modelling procedure}

A staged modelling procedure is adopted to simulate the physical process of pile installation in order to result in correct initial conditions for the subsequent seismic analysis. In the first stage, the soil block without piles is modelled using u-p formulation hexahedron elements with appropriate boundary conditions, and gravity is applied. Fig. 2 shows the soil model for a level ground. If a sloping ground is to be modelled, the $\mathrm{z}$ coordinate of nodes in an original horizontal mesh can be changed to achieve the desired inclination without rotating the entire model. Note that the nodes that are connected with or in the place of the pile and pile cap should not be moved for the sloping models, so that the pile and pile cap to be inserted in the later stage can 
conveniently remain vertical. A close inspection of the calculated initial effective stress (not shown) found that the vertical stress contour is parallel to the inclined ground surface in the far-field, indicating that the slope condition is well simulated. An elastic gravity stage with consolidation is first carried out, during which linear elasticity is used for the soil. The state of the soil is then updated to comply with the proposed plasticity model, and a plastic gravity stage is then conducted to obtain an initial free-field stress.

Next, we use pile and interface elements to replace the soil elements at the specified location. The three displacement degrees of freedom (DOF) of adjacent nodes on the pile and interface are tied together, while the soil and interface elements have an extra pore pressure DOF. Pile caps and superstructures can also be added to the model if necessary (Fig. 2). Another plastic gravity step is subsequently carried out to account for settlement and consolidation caused by pile insertion, generating the proper initial stress field in the soil and piles at a hydrostatic state prior to seismic loading. This procedure does not capture some effects of the pile installation process on soil, such as the stress relaxation for a drilled shaft and soil densification due to driving a highdisplacement pile. These effects are expected to only influence the primary process that we focus on in an insignificant way. After the elastic, plastic, and plastic-with-pile gravity stages, the seismic simulation could then be conducted.

\section{Centrifuge test and finite element simulation setup}

In validation and application of the proposed three dimensional finite element modelling method for piles in liquefiable ground, a series of centrifuge tests and numerical simulations were conducted, as summarized in Table 1. Three centrifuge tests 
on single piles were carried out and simulated, including one in level ground (denoted LCS), one in slightly inclined ground (by $0.75^{\circ}$, denoted ICS), each of which had a superstructure on top of a pile cap fastened to the pile, and one in level ground without pile cap and superstructure (LNN). A fourth scenario of a single pile in level ground with superstructure directly attached without a pile cap (LNS) was simulated numerically for comparison. The superstructure weight in the LNS case was less than the LCS and ICS cases (1.7 ton compared with 10.8 ton in prototype scales). Additionally, the effect of ground inclination and the existence of a non-liquefiable crust layer were also investigated through numerical simulation, by changing the ground inclination within the range of $0.75^{\circ} \sim 6^{\circ}$ and replacing the top $2 \mathrm{~m}$ of the soil in the LCS and LNS models with a non-liquefiable layer respectively (LCS-N and LNSN). In summary, three centrifuge tests (LCS, ICS, and LNN) were performed, and ten numerical models were created: three corresponding to the centrifuge tests and seven additional simulation-only models (including LNS, ICS models with 4 different inclinations, LCS-N, and LNS-N).

The three centrifuge tests were conducted at $30 \mathrm{~g}$ centrifugal acceleration at Tsinghua University's 50 g-ton geotechnical centrifuge facility. The shaking table used on the centrifuge was designed to generate unidirectional horizontal acceleration with a maximum of $20 \mathrm{~g}$, in a frequency range of $10-250 \mathrm{~Hz}$. The shaking motion was along the $\mathrm{x}$-direction in the coordinate system defined in Fig. 2. Fig. 4 shows the setup of the centrifuge tests.

All laboratory dimensions and measurements reported in the current paper have 
been converted to the prototype scale to facilitate engineering interpretation, with the basic scaling factors for dynamic centrifuge modelling [60] provided in Table 2 . The laminar box used in the current study was made of extremely light hollow aluminium rings with interlayer friction coefficient of less than 0.01 (achieved through rollers in between layers). The length-to-depth ratio of the laminar box was 2 to ensure minimal cantilever deformation [61]. The setup and basic properties of the two layer ground model and dimensions of the pile, pile cap, and superstructure shown in Fig.4 have been provided in detail by Wang et al. [43]. A hydroxypropyl methyl cellulose (HPMC) solution with dynamic viscosity 30 times that of water at ambient temperature was used to resolve the discrepancy between the scale factor for dynamic time and consolidation time (table 2). The sand was air pluviated to reach the desired density and then saturated with the HPMC solution under vacuum.

Druck $^{\mathrm{TM}}$ PDCR81 miniature pore pressure transducers was used for pore pressure measurement; Dytran ${ }^{\mathrm{TM}}$ 3035B/BG accelerometers were installed 4 meters from the pile to measure horizontal acceleration; and the strains on the pile was acquired through 7 pairs of strain gauges and the strain values were used to calculate the bending moment. The pore pressure transducers and accelerometers were installed 4 meters from the pile on either side along the centre line of the laminar box at various depths.

The ten 3D finite element simulations were carried out in the prototype length- and time-scale. A half-model cut along the $\mathrm{x}-\mathrm{z}$ plane through the pile centre was used with proper boundary conditions applied on the symmetry plane to take advantage of the symmetry of the problem. Each node on the negative-x boundary share the same DOF 
with the corresponding node on the positive-x boundary to simulate the effects of the laminar box. The tied boundary condition (including modified forms) is widely adopted as a reasonable method for simulating centrifuge experiments using shear beam containers (e.g. [37], [62], and [63]). Free drainage boundary was applied at the ground surface. Input accelerations are forced on the bottom nodes. The pile was simulated using six rows of second order hexahedron elements along the bending direction (x). As no significant bending occurred along the y direction, only one row of elements were sufficient in that direction.

One set of model parameters for sand, interface, pile and structure was used in all the simulations as listed in table 3. The elastic parameters for the pile and structure are typical values for aluminium and steel. For the sand model, the elastic shear modulus parameter $\left(G_{0}\right)$, plastic modulus parameter $(h)$ and critical state stress ratio $(M)$ were calibrated against drained triaxial test data, and the elastic bulk modulus parameter $(\kappa)$ was determined via the rebound curves of triaxial consolidation tests. The critical state parameters $\left(\lambda_{c}, e_{0}, \xi\right)$ for Fujian sand reported by Yang and Sze [64] were used. The dilatancy parameters were back-calculated from the simulation of the LCS centrifuge test and used in the all the other simulations. The interface material parameters were obtained through monotonic interface shear tests under different normal stress using a soil-structure interface test apparatus developed at Tsinghua University [65].

Because the acceleration and excess pore pressure measurements within the sand of test LCS were used to calibrate the model parameters used for all simulations, the comparison of other aspects of model LCS between the centrifuge test and simulation 
and the comparisons for models ICS and LNN are considered validations for the proposed method. The simulation results for LNS, ICS models with 4 different inclinations, LCS-N, and LNS-N are numerical predictions.

\section{Test and simulation results}

\section{LCS, level ground with cap and superstructure}

Fig. 5 displays the calculated and measured horizontal acceleration, excess pore pressure, and pile bending moment histories at various positions in model LCS. All measurements mentioned from hereon were taken on the symmetric x-z plane. Figs. 5 (a)-(b) and 6 depict the accelerations in the time and frequency domains, respectively. The simulated acceleration time histories were taken at the same positions as those of the accelerometers in the centrifuge test, $4 \mathrm{~m}$ from the pile. The maximum input acceleration of model LCS as shown in Fig. 5 (b) was $-4.95 \mathrm{~m} / \mathrm{s}^{2}$, occurring at $6.76 \mathrm{~s}$. The acceleration at the ground surface had a maximum of only $60 \%$ that of the input (Fig. 5 (a)). The Fourier spectra of the input acceleration within two time intervals during the seismic event shows that the input motion between 3 and 5.5 seconds consisted of much greater high frequency components (Fig. 6 (a)) than during 0 to 3 seconds, which was mostly filtered out at ground surface (Fig. 6 (b)) due to the buildup of the excess pore pressure and subsequent softening of the soil. Fig. 5 (c) and (d) show the measured and simulated excess pore pressures at $1.2 \mathrm{~m}$ depth both near and far from the pile. The excess pore pressure in the far-field soil (Fig. 5(c)) generated quickly upon the initiation of the seismic excitation, reaching excess pore pressure ratio 
( $\mathrm{r}_{\mathrm{u}}$, the ratio of excess pore pressure to initial effective stress) of up to 0.6 before 3 seconds. Excess pore pressure generation slowed down significantly between 3 and 5.5 seconds due to attenuation of high frequency acceleration components, even though the input motion intensified after 4 seconds. Simulation result of the near-pile $(0.2 \mathrm{~m}$ from the pile) excess pore pressure time history was significantly different from its far-field counterpart, showing much more fluctuation and the excess pore pressure is overall smaller, owing to the interactions between pile and soil.

The calculated and measured bending moment histories at three different depth are shown in Fig. 5 (e) and (f). The maximum bending moment in the pile was $-58 \mathrm{kNm}$ in the test and $-60 \mathrm{kNm}$ in the simulation. The maximum moment occurred 0.2 seconds later than the peak input acceleration, when the liquefiable had not yet reached liquefaction. No residual moment existed after the seismic motion had ceased. According to the peak positive and negative moment distribution along the pile in Fig. 9, the maximum bending moment was observed at the pile head in the negative direction, while the pile tip was free to rotate and had zero moment. The results of horizontal acceleration, excess pore pressure, and bending moment from numerical simulation all showed good agreement with those gained from centrifuge test. Numerous uncertainties, including velocity effects [66], change in dynamic permeability [67, 68], and sedimentation effects [42], still exist in the simulation of seismic responses of saturated sands. More attention should be paid to these aspects if they are the very focuses of an investigation.

\section{ICS, inclined ground with cap and superstructure}

The calculated and measured results for the model with pile cap and superstructure 
in slightly inclined ground (ICS) are shown in Figs. 8-12. The soil acceleration attenuation (Fig. 8), excess pore pressure build-up (Fig. 9) and pile bending moment (Figs. 11 and 12) are accurately simulated using the proposed method, with exactly the same material parameters as those in the LCS simulation. Similar to the observation in the LCS simulation, the near-pile excess pore pressure during shaking in Fig. 9 (b) is significantly smaller than that of the far-field measurement at the same depth in Fig. 9 (a), echoing the findings in González et al. (2009) [69]. Fig. 10 provides simulated stress-strain relationship from both far-field and near-pile soil, showing that the farfield sand reached liquefaction and most of the shear strain was generated during lateral spreading. On the other hand, the near-pile sand did not quite reach liquefaction but exhibited larger shear stress amplitudes and much stronger dilatancy tendency, likely owing to the interaction between the pile and soil. The near-pile sand also experienced much smaller shear strain during seismic shaking, which concurs with the photo evidence from centrifuge tests by González et al. (2009) [69].

The peak pile moment during the earthquake was $-45 \mathrm{kNm}$ (Fig. 11), which was smaller than that of model LCS partly due to the weaker input motion (maximum input acceleration $-3.8 \mathrm{~m} / \mathrm{s}^{2}$ of ICS vs $-4.95 \mathrm{~m} / \mathrm{s}^{2}$ of LCS). The peak moment distributions of the inclined and level ground models during shaking were very much alike (Figs. 12 (a) and 7). However, the ICS model retained a significant amount of residual moment after the earthquake, reaching $20 \mathrm{kNm}$ at the pile head (Fig. 12 (b)). This residual moment was caused by the lateral spreading of the inclined ground after liquefaction, and amounted to nearly half of the peak moment even in the very gently inclined model 
$\left(0.75^{\circ}\right)$

LNN and LNS, level ground without cap, with and without superstructure

The simulated and measured pile moment histories and peak distribution for the model without pile cap and superstructure in level ground (LNN) are shown in Figs. 13 and 14 , respectively. The acceleration and pore pressure results were very similar to those of the LCS model and are not shown for conciseness. Compared with the LCS model with the same ground and seismic conditions, the pile in the LNN model experienced much smaller bending moments with a maximum of only $5 \mathrm{kNm}$. Since there was no pile cap or superstructure, the bending moment at both the pile head and tip were zero, and the maximum moment occurred at 3-4 m depth.

To comparatively study the influence of the pile cap and superstructure, a model with superstructure but without pile cap (LNS) was simulated numerically. Fig. 14 compares the peak pile moment of the LNS and LNN models. The inertia of the superstructure caused the peak pile moment to be much larger down to $2 \mathrm{~m}$ depth in the LNS model than in the LNN model, with a maximum of $21 \mathrm{kNm}$ at the pile head. However, the peak pile moment below $3 \mathrm{~m}$ depth were almost identical for the two models, which echoes with Gazetas and Dobry's [70] suggestion that the active length of piles under horizontal dynamic loading is $5-15$ times the pile diameter. It is worth noting that under the same seismic excitation, the peak bending moment for the piles in models LNN and LNS were positive, while that in the LCS model was negative. This difference is due to the different interaction modes caused by the pile cap, which will be discussed in the following section. Note that the pile moment values between LNS and LCS should not be compared directly since different superstructure weights were 
used.

\section{Major factors influencing pile responses}

Through numerical simulation of centrifuge model tests, the proposed three dimensional finite element modelling method for piles in liquefiable ground have exhibited excellent capabilities in reproducing the dynamic response of the soil-pile system under seismic loading. Hence the method can be further applied to investigating behaviour of piles in liquefiable ground, including the effects of pile cap, lateral spreading, and non-liquefiable surface layer.

\section{Pile cap}

Simulation results for models LCS and LNS have shown that under the same ground conditions and seismic input, single piles with and without pile cap experienced peak bending moments of opposite directions. Fig. 15 shows that pile moment was strongly correlated to the displacement of soil and structure acceleration in both models, with the peak moment occurring at maximum positive surface soil displacement and negative structure acceleration. However, for the case with pile cap (LCS) the moment was negatively correlated to soil displacement and positively correlated to structure acceleration, which was opposite to the case without pile cap (LNS).

This difference in pile moment direction is a result of the difference in bending modes caused by the pile cap. Fig. 16 shows the pile slope at the time of peak pile moment in model LCS and LNS. The pile slope is defined as $\mathrm{d} \omega / \mathrm{d} y$, where $\omega$ is the pile displacement in the x-direction. Under the same soil displacement and inertial force directions, the pile bent towards opposite directions with and without pile cap. While 
the slope at pile tip were close for both LCS and LNS cases, the LCS had a very small slope at the pile head making it almost vertical, and the slope at the pile head was greater than that at the pile tip for LNS. This means that the pile cap restricts the rotation of the pile head and thus causes the pile to bend as illustrated in Fig. 17 (a), whereas without the constraint of the cap, the pile would bend in the manner of Fig. 17 (b). The different bending modes hence lead to different pile moment distributions. Bending modes influence the role of inertial and kinematic interactions in different pile model setups, and should be further investigated in future studies. Variations in pile cap size and modulus are expected to influence the magnitude of the constraint at the pile head and thus influence the response of piles.

\section{Lateral spreading}

Test and simulation results of the ICS model showed that lateral spreading of liquefiable ground could cause significant residual pile moment. Four models with different ground inclinations $\left(1.5^{\circ}, 2.25^{\circ}, 3^{\circ}\right.$, and $\left.6^{\circ}\right)$ but otherwise identical to ICS were numerically simulated to study this effect. Fig. 18 shows the evolutions of the residual maximum pile moment, residual soil surface displacement, residual pile head displacement, and pile-soil relative displacement with respect to the ground inclination angle. As the ground slope increased, both the amount of lateral spreading and residual pile bending moment increased. The $p-y$ curves at $1.5 \mathrm{~m}$ depth in models ICS $\left(0.75^{\circ}\right)$ and $\operatorname{ICS}_{5}\left(6^{\circ}\right)$ were back-calculated from the simulation results (Fig. 19), with the soil resistance obtained by calculating the second order derivative of bending moment with respect to the depth. Comparison of the $p-y$ curves in the two simulations shows that the soil resistance during lateral spreading in the model with more ground inclination 
$\left(\mathrm{ICS}_{5}\right)$ is significantly greater and continues to increase with increasing displacement, while the soil resistance was much smaller and peaked early in the ICS model, similar to the observations by Abdoun et al. in centrifuge test $2^{\circ}$ ground inclination [71]. Further investigation into the excess pore pressure time history in model $\mathrm{ICS}_{5}$ shows that sand at $1.5 \mathrm{~m}$ depth from ground surface first reached liquefaction, but the excess pore pressure gradually decreased after about $7.5 \mathrm{~s}$ (Fig. 20), suggesting that near-surface sand had regained effective stress during lateral spreading. The stress strain relationship at the same position further confirms this observation, showing that as the surface sand dilates during lateral spreading, it regains effective stress (Fig. 21), which is a very important feature of post-liquefaction shear deformation of sand captured by the current constitutive model.

The increase in effective stress, combined with greater relative lateral displacement between pile and soil, causes the residual pile bending moment to increase with increased ground inclination. For the given material and structure, a ground inclination angle above $2^{\circ}$ was sufficient to generate a residual moment greater than the peak moment during shaking, which explains the observed pile foundation failures that occurred during lateral spreading, and suggests that current design methods which do not take into consideration of the change in effective stress of sand during lateral spreading may underestimate the forces that are enforced onto the piles.

\section{Non-liquefiable crust}

A non-liquefiable crust can often be found above liquefiable soil. The effect of a stiff non-liquefiable crust is here studied by replacing the top $2 \mathrm{~m}$ of the LCS and LNS models with a non-liquefiable layer to create models LCS-N and LNS-N. In the current 
simulations, the crust is modelled using linear elasticity, with a Young's modulus of $30 \mathrm{MPa}$ and Poisson's ratio of 0.4 , which is aimed to provide a basic understanding of the effect of a relatively stiff non-liquefiable crust, more advanced material model should be used in further in-depth analyses of the influence of the crust layer.

In the LCS-N model, the maximum moment of the pile occurred near the interface between the non-liquefiable and liquefiable layers instead of at the pile head, and was significantly greater than that of the LCS model (Fig. 22). The LNS-N showed similar results of maximum moment occurring at the soil layer interface. However, the direction of the moment at the soil layer interface was opposite to that at the pile head (Fig. 23), which is again related to the constraint on pile rotation. Fig. 24 compares the pile slopes at peak pile moment of models LCS-N and LNS-N against their respective counterparts without non-liquefiable layers. The comparison shows that the existence of a non-liquefiable crust acts as a weak constraint on the pile rotation within the layer, causing the bending and pile moment to intensify at the interface between nonliquefiable and liquefiable layers, which has been the observation in many case histories (e.g. $[72,73])$.

\section{Summary and Conclusions}

A three dimensional finite element modelling method for piles in liquefiable ground was developed in the current study. The method was validated against centrifuge shaking table tests, and subsequently employed in the study of the seismic response of piles. A plasticity model for large post-liquefaction shear deformation of sand was formulated and efficiently implemented to provide a unified description of sand from 
pre- to post-liquefaction under monotonic and cyclic loading. Second order twenty node brick elements were used for the piles and a hyperbolic model for the soil-pile interface to provide appropriate physical representation of the soil-pile system. A staged modelling procedure was adopted for the method to provide correct initial conditions for the seismic analysis.

Three centrifuge shaking table tests on single piles with and without pile cap and superstructure, in level and inclined liquefiable grounds were conducted and simulated. The results of numerical simulation showed good agreement with the centrifuge test measurements of the accelerations and excess pore pressures within the soil, and especially the bending moments of the piles.

Some of the major factors for the seismic pile response in liquefiable ground observed in the centrifuge tests and past case histories were investigated using the proposed method. The existence of the pile cap was found to restrain the rotation of the pile head, change the bending mode of the pile, and hence cause piles with and without pile cap to experience bending moments of opposite directions. Inclined ground was found to increase lateral spreading of liquefied ground, and in turn result in greater pile residual moment. Even a modestly inclined ground was sufficient to generate a residual moment greater than the peak bending moment of a pile in a level but otherwise identical ground. The existence of a non-liquefiable crust restricts the pile rotation within the layer, causing the bending and pile moment to intensify at the interface between non-liquefiable and liquefiable layers.

The current study has provided a method that has been applied on the analysis of 
single piles in liquefiable ground, which can be further extended to more widely used pile group foundations for more comprehensive analysis of the combined effects of structure inertia and soil-pile kinematic interaction. The current work's simulation of single piles with pile caps provides important baseline results for future group pile studies, although single-pile cap is less often used in engineering practice.

\section{Acknowledgements}

The authors would like to thank the National Natural Science Foundation of China (No. 51079074 and No. 51038007) and the China Postdoctoral Science Foundation (2015M570106) for funding the work presented in this paper. Fu's work was partly performed under the auspices of the U.S. Department of Energy by Lawrence Livermore National Laboratory under Contract DE- AC52-07NA27344.

\section{References}

[1] Ross G, Seed, HB, Migliacio R. Performance of highway bridge foundations in the great Alaska earthquake of 1964. Committee on the Alaskan Earthquake of the Division of Earth Sciences National Research Council. The Great Alaska Earthquake of 1964. National Academy of Sciences, Washington D.C., 1973.

[2] Hamada M. Large Ground Deformations and their Effects on Lifelines: 1964 Niigata Earthquake. Case Studies of Liquefaction and Lifelines Performance during Past Earthquake. Technical Report NCEER-92-0001, National Centre for Earthquake Engineering Research, Buffalo, 1992. 
[3] Ishihara K. Terzaghi oration: Geotechnical aspects of the 1995 Kobe earthquake. Proceedings of the International Conference on Soil Mechanics and Foundation Engineering, Hamburg, 1997: 2047-2073.

[4] Tokimatsu K, Hiroshi O, Satake K, Shamoto Y, Asaka Y. Effects of lateral ground movements on failure patterns of piles in the 1995 Hyogoken-Nambu earthquake. Proceedings of a Speciality Conference, Geotechnical Earthquake Engineering and Soil Dynamics III, ASCE Geotechnical Special Publication, 1998, 75: 1175-1186.

[5] Stewart JP, Brandenberg SJ. Preliminary report on seismological and geotechnical engineering aspects of the April 42010 mw 7.2 El MayorCucapah (Mexico) earthquake. Report of the National Science FoundationSponsored Geoengineering Extreme Events Reconnaissance (GEER) Team, 2010 .

[6] Yen WP, Chen G, Buckle I, Allen T, Alzamora D, Ger J, Arias JG. Postearthquake reconnaissance report on transportation infrastructure: impact of the February 27, 2010, Offshore Maule Earthquake in Chile. FHWA-HRT11-030, Federal Highway Administration, Virginia, 2011.

[7] Tokimatsu K, Tamura S, Suzuki H, Katsumata K. Building damage associated with geotechnical problems in the 2011 Tohoku Pacific Earthquake. Soils and Foundations, 2012, 52(5): 956-974.

[8] Japan Road Association (JRA). Specifications for highway bridges. Public Works Research Institute and Civil Engineering Research Laboratory, Tokyo, 2002.

[9] Dobry R, Abdoun T, O'Rourke TD, Goh SH. Single piles in lateral spreads: Field bending moment evaluation. Journal of Geotechnical and Geoenvironmental Engineering, 2003, 129(10): 879-889.

[10] Reese LC, Matlock H. Nondimensional solutions for laterally loaded piles with soil modulus assumed proportional to depth. Austin: Proceedings of the 
VIII Texas Conference on Soil Mechanics and Foundation Engineering, 1956.

[11] McClelland B, Focht JA Jr. Soil Modulus for laterally loaded piles. Transactions, ASCE, 1958, 123: 1049-1086.

[12] Matlock H. Correlations for design of laterally loaded piles in soft clay. Proceedings of the II Annual Offshore Technology Conference, Houstion, 1970: 577-594.

[13] Reese LC, O'Neill MW. Drilled Shafts: Construction Procedures and Design Methods. Report No. FHWA-HI-88-042. Virginia: U.S. Department of Transportation, Federal Highway Administration, Office of Implementation, 1988.

[14] American Petroleum Institute (API). Recommended Practice or Planning, Designing, and Constructing Fixed Offshore Platforms-Working Stress Design. API Recommennded Practice, 2A (WSD), 2000.

[15] Architectural Institute of Japan (AIJ). Recommendations for design of building foundations. AIJ, Tokyo, 2001. (In Japanese).

[16] Brandenberg SJ, Boulanger RW, Kutter BL, Chang D. Static pushover analyses of pile groups in liquefied and laterally spreading ground in centrifuge tests. Journal of Geotechnical and Geoenvironmental Engineering, 2007, 133(9): 1055-1066.

[17] Rollins KM, Gerber TM, Lane JD, Ashford S A. Lateral resistance of a fullscale pile group in liquefied sand. Journal of Geotechnical and Geoenvironmental Engineering, 2005, 131(1): 115-125.

[18] Cubrinovski M, Kokusho T, Ishihara K. Interpretation from large-scale shake table tests on piles undergoing lateral spreading in liquefied soils. Soil Dynamics and Earthquake Engineering, 2006, 26(2-4): 275-286.

[19] Liyanapathirana DS, Poulos HG. Pseudostatic approach for seismic analysis of piles in liquefying soil. Journal of Geotechnical and Geoenvironmental Engineering, 2005, 131(12): 1480-1487. 
[20] Tokimatsu K, Suzuki H, Sato M. Effects of inertial and kinematic interaction on seismic behaviour of pile with embedded foundation. Soil Dynamics and Earthquake Engineering, 2005, 25: 753-762.

[21] California Department of Transportation (Caltrans). Guidelines on foundation loading and deformation due to liquefaction induced lateral spreading. California, 2013.

[22] Boulanger RW, Curras CJ, Kutter BL, Wilson DW, Abghari A. Seismic soilpile-structure interaction experiments and analysis. Journal of Geotechnical and Geoenvironmental Engineering, 1999, 125(9): 750-759.

[23] Brandenberg SJ, Zhao M, Boulanger RW, Wilson DW. p-y Plasticity Model for Nonlinear Dynamic Analysis of Piles in Liquefiable Soil. Journal of Geotechnical and Geoenvironmental Engineering, 2012, 139(8): 1262-1274.

[24] Varun. A non-linear dynamic macroelement for soil structure interaction analyses of piles in liquefiable sites. $\mathrm{PhD}$ Thesis. Georgia Institute of Technology, Atlanta, 2010.

[25] Finn WDL. An Overview of the behaviour of pile foundations in liquefiable and non-liquefiable soils during earthquake excitation. Proceedings of the 11th International Conference on Soil Dynamics \& Earthquake Engineering, Berkeley, 2004.

[26] Finn WDL, Fujita N. Piles in liquefiable soils: seismic analysis and design issues. Soil Dynamics and Earthquake Engineering, 2002, 22(9-12): 731-742.

[27] Wotherspoon LM. Three dimensional pile finite element modelling using OpenSees. 2006 NZSEE Conference Proceedings, Napier, 2006.

[28] Sanchez M, Roesset JM. Evaluation of models for laterally loaded piles. Computers and Geotechnics, 2013(48): 316-320.

[29] Cheng Z, Jeremic B. Numerical modeling and simulation of pile in liquefiable soil. Soil Dynamics and Earthquake Engineering, 2009, 29(11): 1405-1416. 
[30] Lu J, Elgamal A, Yan L, Law KH, Conte JP. Large-scale numerical modeling in geotechnical earthquake engineering. International Journal of Geomechanics, 2011, 11(6): 490-503.

[31] Jie YX, Yuan HN, Zhou HD, Yu YZ. Bending moment calculations for piles based on the finite element method. Journal of Applied Mathematics, 2013.

[32] Byrne PM, Debasis R, Campanella RG, Hughes J. Predicting Liquefaction Response of Granular Soils from Self-Boring Pressuremeter Tests, Proceedings of the Conference on Static and Dynamic Properties of Gravely Soils, ASCE National Convention, San Diego, California, 1995, GSP No. 56: $122-135$.

[33] Beaty MH. A Synthesized Approach for Estimating Liquefaction-Induced Displacements of Geotechnical Structures. Ph.D. Thesis. University of British Columbia, Vancouver, Canada, 2001.

[34] Pastor M, Zienkiewicz OC, Chan A. Generalized plasticity and the modelling of soil behaviour. International Journal for Numerical and Analytical Methods in Geomechanics, 1990, 14(3): 151-190.

[35] Zienkiewicz O C, Mroz Z. Generalized plasticity formulation and application to geomechanics. Mech. Eng. Materials (Desai C S, Gallagher RH eds), John Wiley \& Sons, 1984, 655-679.

[36] Parra-Colmenares EJ. Numerical modeling of liquefaction and lateral ground deformation including cyclic mobility and dilation response in soil systems, Ph.D. Thesis, Rensselaer Polytechnic Institute, Troy, New York, 1996.

[37] Elgamal A, Yang Z, Parra E. Computational modeling of cyclic mobility and post-liquefaction site response. Soil Dynamics and Earthquake Engineering, 2002, 22(4): 259-271.

[38] Wang ZL, Dafalias YF, Shen CK. Bounding surface hypoplasticity model for sand. Journal of Engineering Mechanics, 1990, 116(5): 983-1001. 
[39] Papadimitriou AG, Bouckovalas GD, Dafalias YF. Plasticity model for sand under small and large cyclic strains. Journal of Geotechnical and Geoenvironmental Engineering, 2001, 127(11): 973-983.

[40] Dafalias YF, Manzari MT. Simple plasticity sand model accounting for fabric change effects. Journal of Engineering Mechanics, 2004, 130(6): 622-634.

[41] Taiebat M, Jeremić B, Dafalias YF, Kaynia AM, Cheng Z. Propagation of seismic waves through liquefied soils. Soil Dynamics and Earthquake Engineering, 2010, 30(4): 236-257.

[42] Boulanger RW, Ziotopoulou K. Formulation of a sand plasticity plane-strain model for earthquake engineering applications. Soil Dynamics and Earthquake engineering, 2013, 53: 254-267.

[43] Wang R, Zhang JM, Wang G. A unified plasticity model for large postliquefaction shear deformation of sand. Computers and Geotechnics, 2014, 59: 54-66.

[44] Kutter BL, Chen Y, Shen CK. Triaxial and torsional shear test results for sand. Naval Facilities Engineering Service Center, Contact Report CR 94.003-SHR, Port Hueneme, California, 1994.

[45] Zhang JM. Cyclic critical stress state theory of sand with its application to geotechnical problems, PhD thesis, Tokyo Institute of Technology, Tokyo, 1997.

[46] Chiaro G, Kiyota T, Koseki J. Strain localization characteristics of loose saturated Toyoura sand in undrained cyclic torsional shear tests with initial static shear. Soils and Foundations, 2013, 53(1): 23-34.

[47] Dafalias YF, Popov EP. A model of nonlinearly hardening materials for complex loading. Acta Mechanica, 1975, 21(3): 173-192.

[48] Shamoto Y, Zhang JM. Mechanism of large post-liquefaction deformation in saturated sands. Soils and Foundations 1997, 2(37): 71-80.

[49] Zhang JM. Reversible and irreversible dilatancy of sand. Chinese Journal of Geotechnical Engineering 2000, 1(22): 12-17. 
[50] Kutter, B. L., Chen, Y., Shen, C. K. Triaxial and torsional shear test results for sand., Naval Facilities Engineering Service Center, Contact Report CR 94.003-SHR, Port Hueneme, California, 1994.

[51] Simo JC, Ortiz M. A unified approach to finite deformation elastoplastic analysis based on the use of hyperelastic constitutive equations. Computer Methods in Applied Mechanics and Engineering 1985, 49(2): 221-245.

[52] Pande GN, Pietruszczak ST. Symmetric tangential stiffness formulation for non-associated plasticity. Computers and Geotechnics, 1986, 2(2): 89-99.

[53] Xiong WL. Symmetric formulation of tangential stiffnesses for nonassociated plasticity. Applied Mathematics and Mechanics, 1986, 7(11): $1043-52$.

[54] Luo T, Qin Z, Feng X, Xia F, Yao Y, Sheng D. A symmetrisation method for non-associated unified hardening model. Computers and Geotechnics, 2013, 52: $38-45$.

[55] McKenna F, Fenves GL. OpenSees Manual., PEER Center, http://OpenSees.berkeley.edu, 2001.

[56] Yang Z, Lu J, Elgamal A. OpenSees soil models and solid-fluid fully coupled elements user manual. University of California, San Diego, California, 2008.

[57] Zienkiewicz OC, Chang CT, Bettess P. Drained, undrained, consolidating and dynamic behaviour assumptions in soils. Geotechnique, 1980, 30(4): 385395.

[58] Zienkiewicz OC, Chan AHC, Pastor M, Schrefler BA, Shiom T. Computational geomechanics with special reference to earthquake engineering. John Wiley \& Sons, Chichester, 1999.

[59] Clough GW, Duncan JM. Finite element analyses of retaining wall behaviour. Journal of the Soil Mechanics and Foundations Division, 1971, 97(12): 16571673.

[60] Kutter BL. Dynamic centrifuge modeling of geotechnical structures. Transportation research record, 1992, 1336: 24-30. 
[61] Hushmand BR, Scott F, Crouse C B. Centrifuge liquefaction tests in a laminar box. Geotechnique, 1988, 38(2): 253-262.

[62] Andrianopoulos KI, Papadimitriou AG, Bouckovalas GD. Bounding surface plasticity model for the seismic liquefaction analysis of geostructures. Soil Dynamics and Earthquake Engineering, 2010, 30(10): 895-911.

[63] Chaloulos YK, Bouckovalas, GD, Karamitros DK. Pile response in submerged lateral spreads: common pitfalls of numerical and physical modeling techniques. Soil Dynamics and Earthquake Engineering, 2013, 55: 275-287.

[64] Yang J, Sze HY. Cyclic strength of sand under sustained shear stress. Journal of Geotechnical and Geoenvironmental Engineering 2011; 137: 1275-1285.

[65] Zhang G, Zhang JM. Large-scale apparatus for monotonic and cyclic soilstructure interface test. Geotechnical Testing Journal, 2006, 29(5): 401-8.

[66] Zhang JM, Wang G. Large post-liquefaction deformation of sand, part I: physical mechanism, constitutive description and numerical algorithm. Acta Geotechnica, 2012, 7(2): 69-113.

[67] Shahir H, Pak A, Taiebat M, and Jeremic B. Evaluation of variation of permeability in liquefiable soil under earthquake loading. Computers and Geotechnics, 2012, 40: 74--88.

[68] Liu L, Dobry R. Seismic response of shallow foundation on liquefiable sand. Journal of Geotechnical and Geoenvironmental Engineering, 1997, 123(6): $557-566$.

[69] González L, Abdoun T, Dobry R. Effect of soil permeability on centrifuge modeling of pile response to lateral spreading. Journal of Geotechnical and Geoenvironmental Engineering, 2009, 135(1): 62-73.

[70] Gazetas G, Dobry R. Horizontal response of piles in layered soils. Journal of Geotechnical Engineering, 1984, 110(1): 20-40. 
[71] Abdoun T, Dobry R, O'Rourke TD, Goh SH. Pile response to lateral spreads: Centrifuge modeling. Journal of Geotechnical and Geoenvironmental Engineering, 2003, 129(10): 869-878.

[72] Berrill J, Yasuda S. Liquefaction and piled foundations: some issues. Journal of Earthquake Engineering, 2002, 6(S1): 1-41.

[73] Madabhushi G, Knappett J, Haigh S. Design of pile foundations in liquefiable soils. Imperial College Press, London, 2010. 
Fig. 1. Simulation of undrained cyclic torsional stress path and stress-strain relation of Nevada sand (Experiment data from Kutter et al., 1994).

Fig. 2. Diagram of staged modelling technique for three dimensional finite element simulation of piles in liquefiable ground.

Fig. 3. Validation of moment and deflection calculation method using 6 twenty-node brick elements in a cross section

Fig. 4. Diagram of centrifuge model tests for single piles in liquefiable ground (dimensions in $\mathrm{cm})$.......

Fig. 5. Horizontal acceleration, excess pore pressure and pile moment histories at various positions in centrifuge test and numerical simulation of model LCS: (a) acceleration at ground surface; (b) input acceleration at the base; (c) excess pore pressure at $1.2 \mathrm{~m}$ depth, $4.0 \mathrm{~m}$ from pile; (d) excess pore pressure at $1.2 \mathrm{~m}$ from ground surface, $0.2 \mathrm{~m}$ from pile; (e) pile moment at $0.45 \mathrm{~m}$ depth; (f) pile moment at $2.25 \mathrm{~m}$ depth. ((a), (b), (c), (e), and (f) from Wang et al. 2014, with permission from Elsevier)

Fig. 6. Fourier amplitudes for: (a) input acceleration within two time intervals; (b) surface (simulated result) and input acceleration.

Fig. 7. Two snapshots of the bending moment distribution along the pile in model LCS, taken at the instances when peak positive and negative bending moment occurred. (Negative moment distribution from Wang et al., 2014)

Fig. 8. Horizontal acceleration histories at various depths from centrifuge test and numerical simulation on model ICS: (a) at ground surface; (b) at $5 \mathrm{~m}$ from ground surface; (c) input acceleration at the base.

Fig. 9. Excess pore pressure histories at various depths and distance from pile in centrifuge test and numerical simulation on model ICS: (a) at $1.2 \mathrm{~m}$ from ground surface, $4.0 \mathrm{~m}$ from pile; (b) at $1.2 \mathrm{~m}$ from ground surface, $0.2 \mathrm{~m}$ from pile; (c) at $4.2 \mathrm{~m}$ from ground surface, 4.0 $\mathrm{m}$ from pile.

Fig. 10. Simulated stress strain relationship $2.6 \mathrm{~m}$ from ground surface for model ICS: (a) 4.0 $\mathrm{m}$ from pile; (b) $0.2 \mathrm{~m}$ from pile

Fig. 11. Pile moment histories at various depths from centrifuge test and numerical simulation on model ICS: (a) at $0.45 \mathrm{~m}$ from ground surface; (b) at $2.55 \mathrm{~m}$ from ground surface; (c) at $5.85 \mathrm{~m}$ from ground surface.

Fig. 12. Two snapshots of the bending moment distribution along the pile in model ICS, taken when peak and maximum residual bending moment occurred.

Fig. 13. Pile moment histories at various depths from centrifuge test and numerical simulation on model LNN: (a) at $1.50 \mathrm{~m}$ from ground surface; (b) at $3.30 \mathrm{~m}$ from ground surface; (c) at $5.85 \mathrm{~m}$ from ground surface. 
Fig. 14. Two snapshots of the bending moment distribution along the pile in model LNN and LNS respectively (Numerical simulation only for LNS), taken when peak bending moment occurred in each model.

Fig. 15. Relationship between surface soil displacement, structure acceleration and pile

Fig. 16. Pile slope at the time of peak pile moment in model LCS and LNS.

Fig. 17. Effect of pile cap on pile head rotation and pile moment.

Fig. 18. Effect of ground inclination on residual pile and soil response: (a) residual maximum pile moment; (b) residual soil surface, pile head and pile-soil relative displacement. 53

Fig. 19. Back calculated soil resistance $(p-y)$ curve in FEM simulation of models ICS and $\mathrm{ICS}_{5}$. 54

Fig. 20. Simulated excess pore pressure time history of model $\mathrm{ICS}_{5}$ 55

Fig. 21. Simulated stress strain relationship $1.5 \mathrm{~m}$ from ground surface and $4.0 \mathrm{~m}$ from pile for model ICS 5 56

Fig. 22. Comparison between the peak moment distribution of models LCS-N and LCS. .... 57

Fig. 23. Comparison between the peak moment distribution of models LNS-N and LNS..... 58

Fig. 24. Effect of non-liquefiable crust on pile head rotation. 59

Table 1. Centrifuge test and numerical simulation program 60

Table 2. Centrifuge shaking table test scale factors 61

Table 3. Material parameters used in simulations 62 

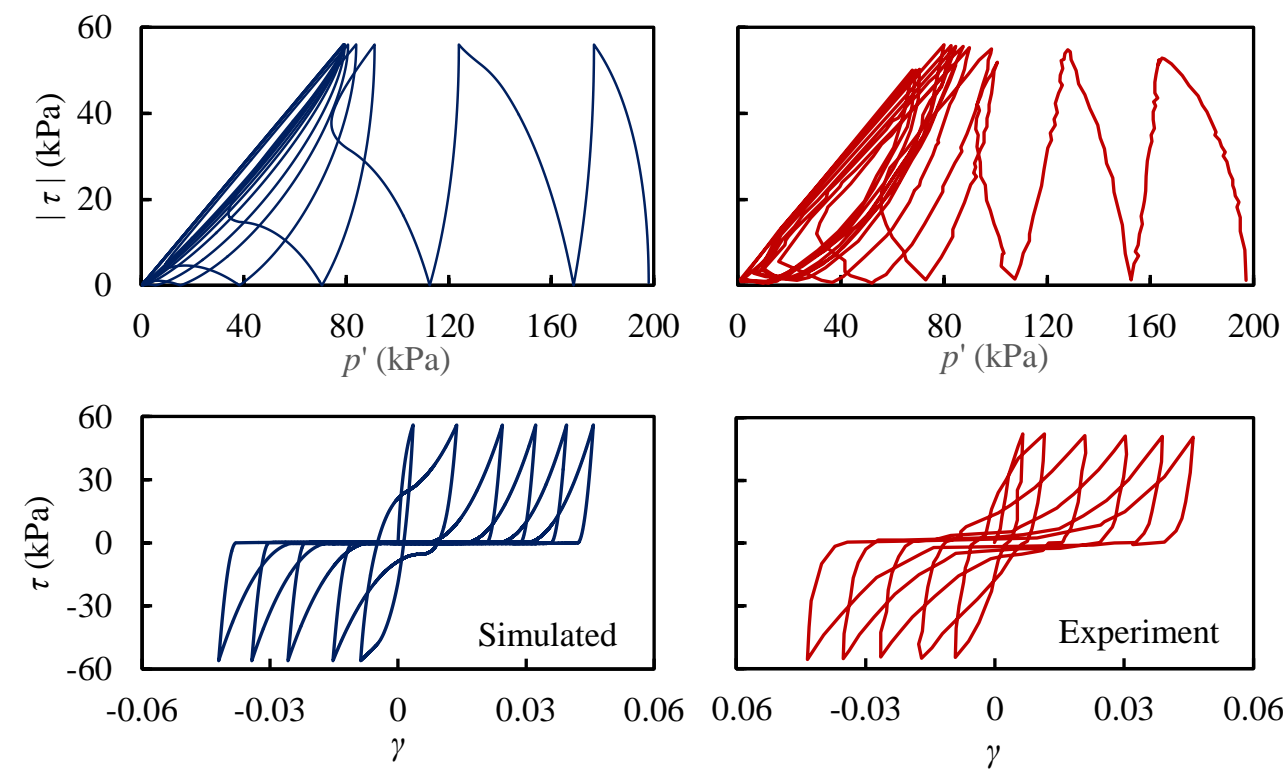

Fig. 1. Simulation of undrained cyclic torsional stress path and stress-strain relation of Nevada sand (Experiment data from Kutter et al., 1994). 

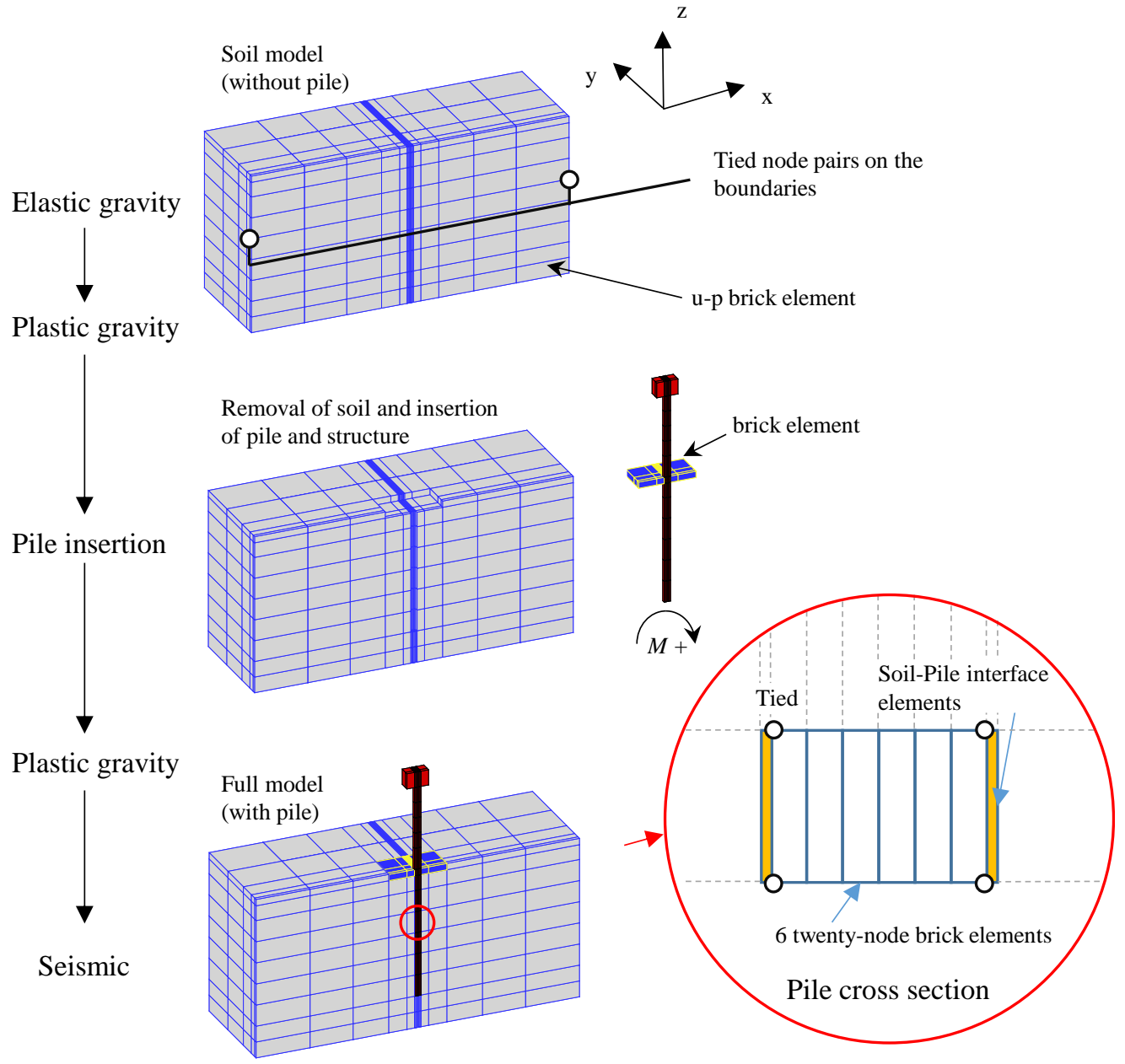

Fig. 2. Diagram of staged modelling technique for three dimensional finite element simulation of piles in liquefiable ground 

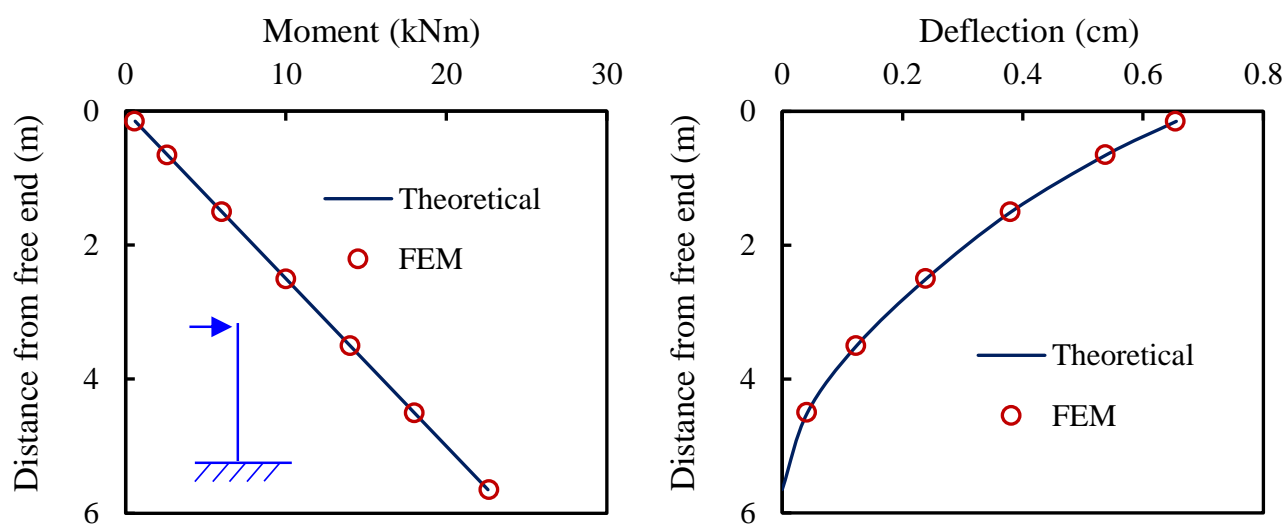

Fig. 3. Validation of moment and deflection calculation method using 6 twenty-node brick elements in a cross section 


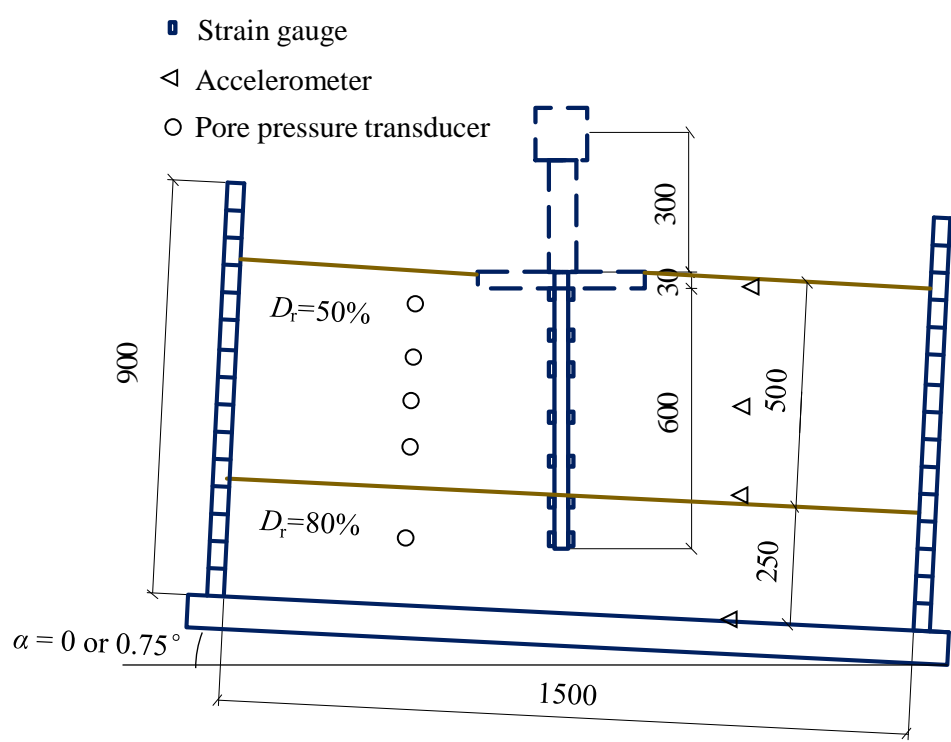

Fig. 4. Diagram of centrifuge model tests for single piles in liquefiable ground (dimensions in $\mathrm{cm}$ ). 

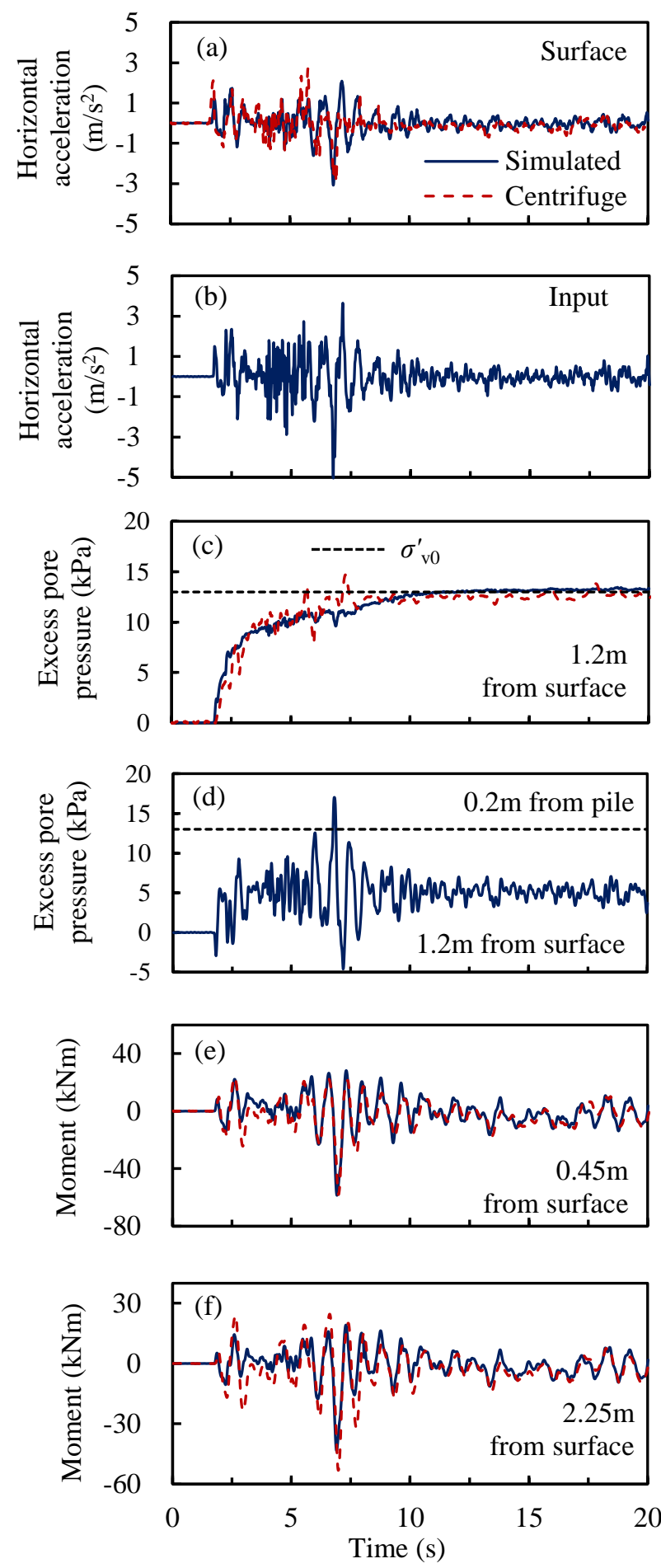
Fig. 5. Horizontal acceleration, excess pore pressure and pile moment histories at various positions in centrifuge test and numerical simulation of model LCS: (a) acceleration at ground surface; (b) input acceleration at the base; (c) excess pore pressure at $1.2 \mathrm{~m}$ depth, $4.0 \mathrm{~m}$ from pile; (d) excess pore pressure at $1.2 \mathrm{~m}$ from ground surface, $0.2 \mathrm{~m}$ from pile; (e) pile moment at $0.45 \mathrm{~m}$ depth; (f) pile moment at $2.25 \mathrm{~m}$ depth. ((a), (b), (c), (e), and (f) from Wang et al. 2014, with permission from Elsevier) 

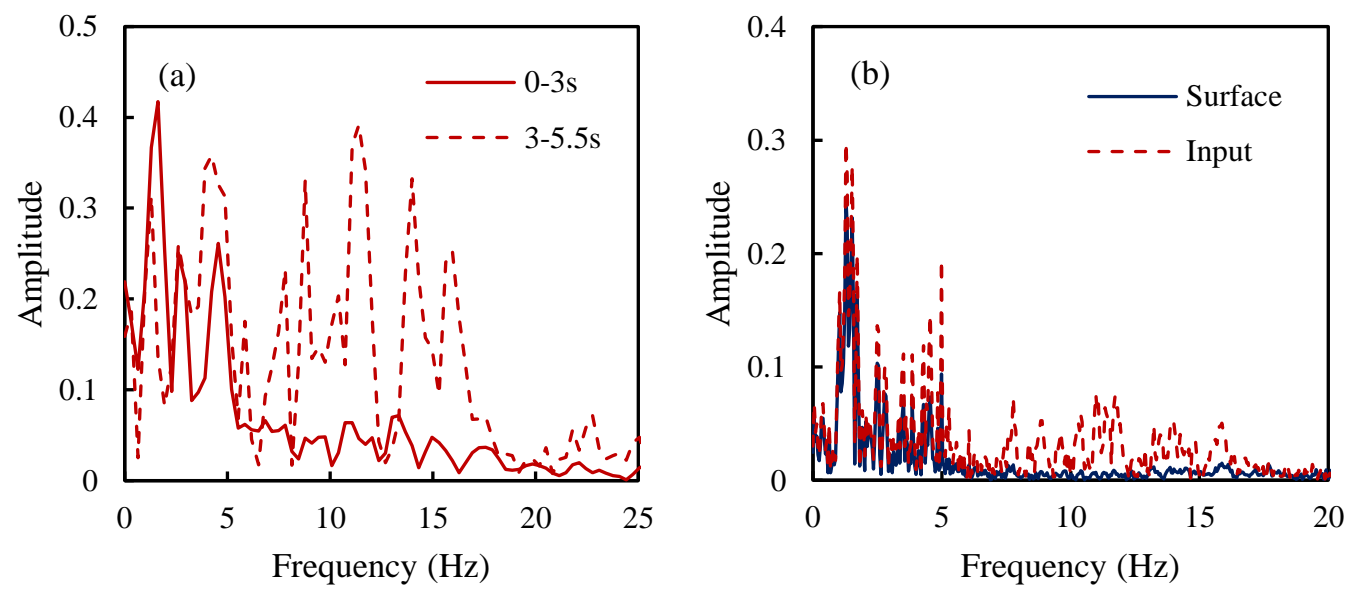

Fig. 6. Fourier amplitudes for: (a) input acceleration within two time intervals; (b) surface (simulated result) and input acceleration. 


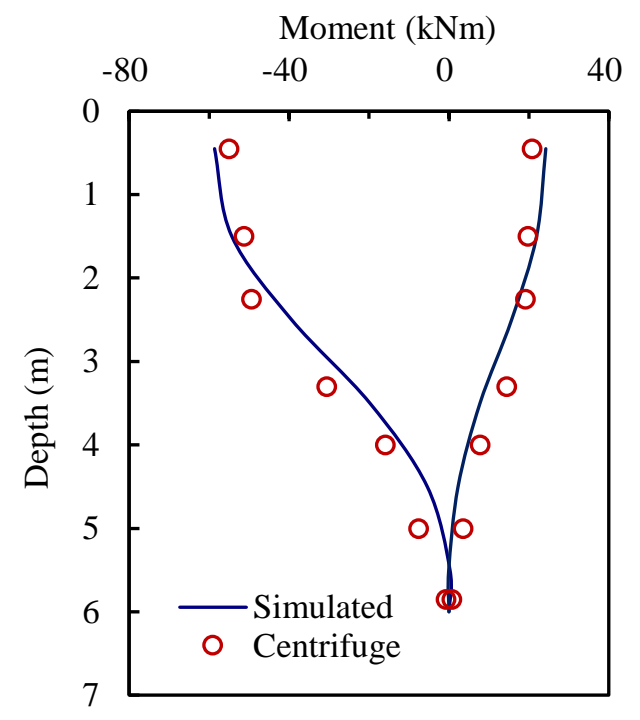

Fig. 7. Two snapshots of the bending moment distribution along the pile in model LCS, taken at the instances when peak positive and negative bending moment occurred. (Negative moment distribution from Wang et al., 2014) 

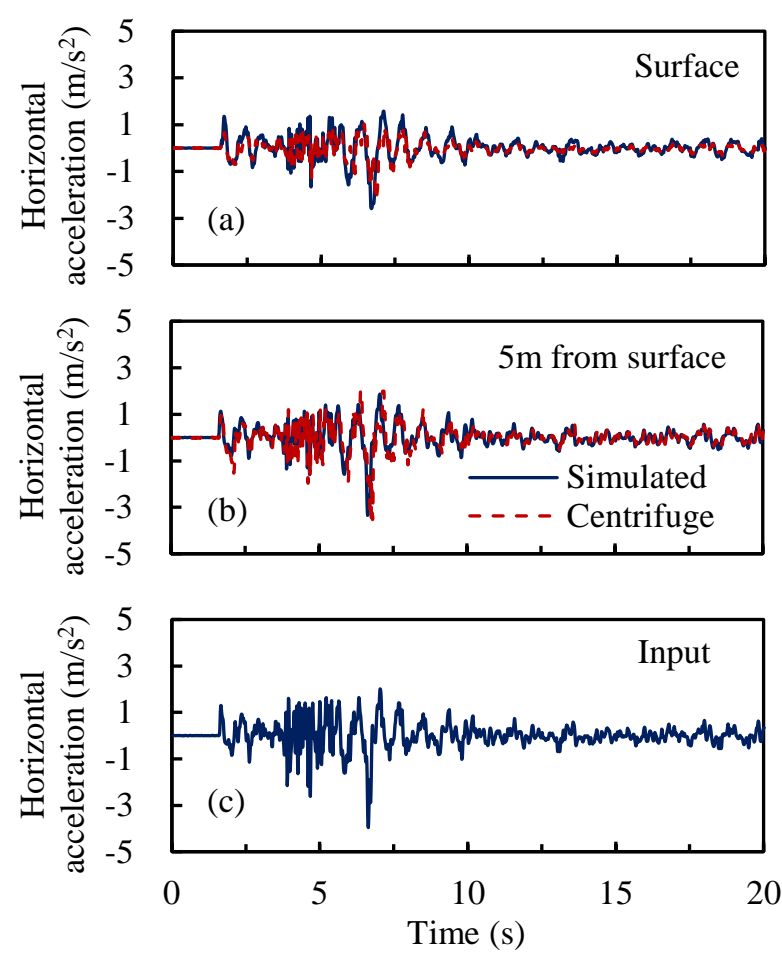

Fig. 8. Horizontal acceleration histories at various depths from centrifuge test and numerical simulation on model ICS: (a) at ground surface; (b) at $5 \mathrm{~m}$ from ground surface; (c) input acceleration at the base. 

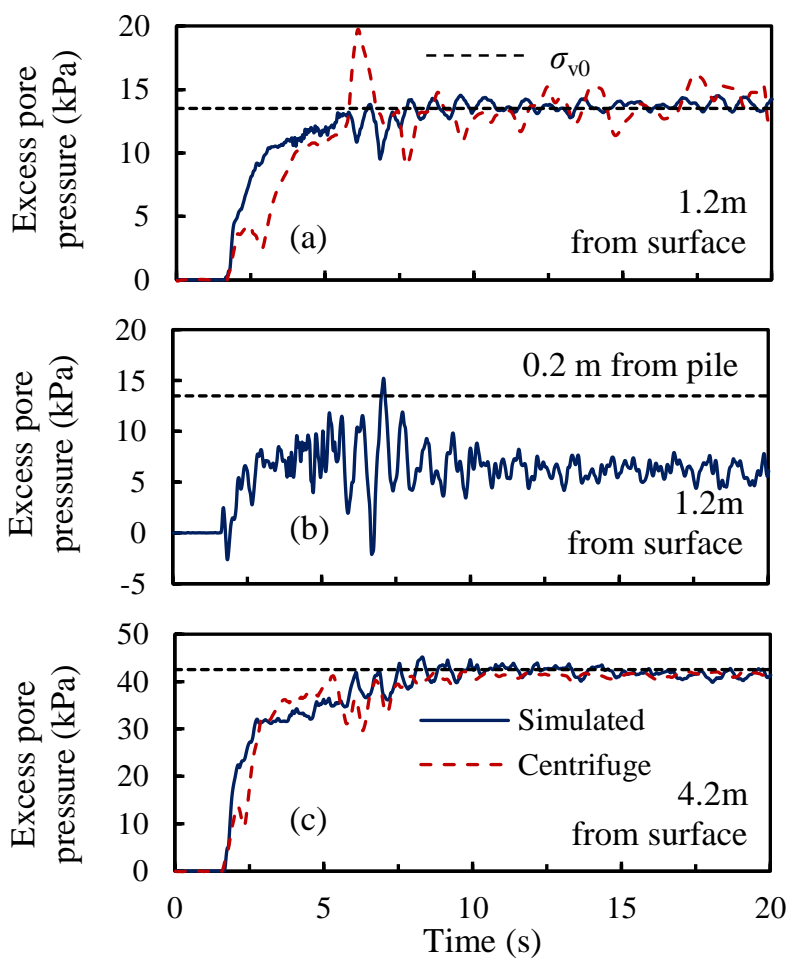

Fig. 9. Excess pore pressure histories at various depths and distance from pile in centrifuge test and numerical simulation on model ICS: (a) at $1.2 \mathrm{~m}$ from ground surface, $4.0 \mathrm{~m}$ from pile; (b) at $1.2 \mathrm{~m}$ from ground surface, $0.2 \mathrm{~m}$ from pile; (c) at 4.2 $\mathrm{m}$ from ground surface, $4.0 \mathrm{~m}$ from pile. 

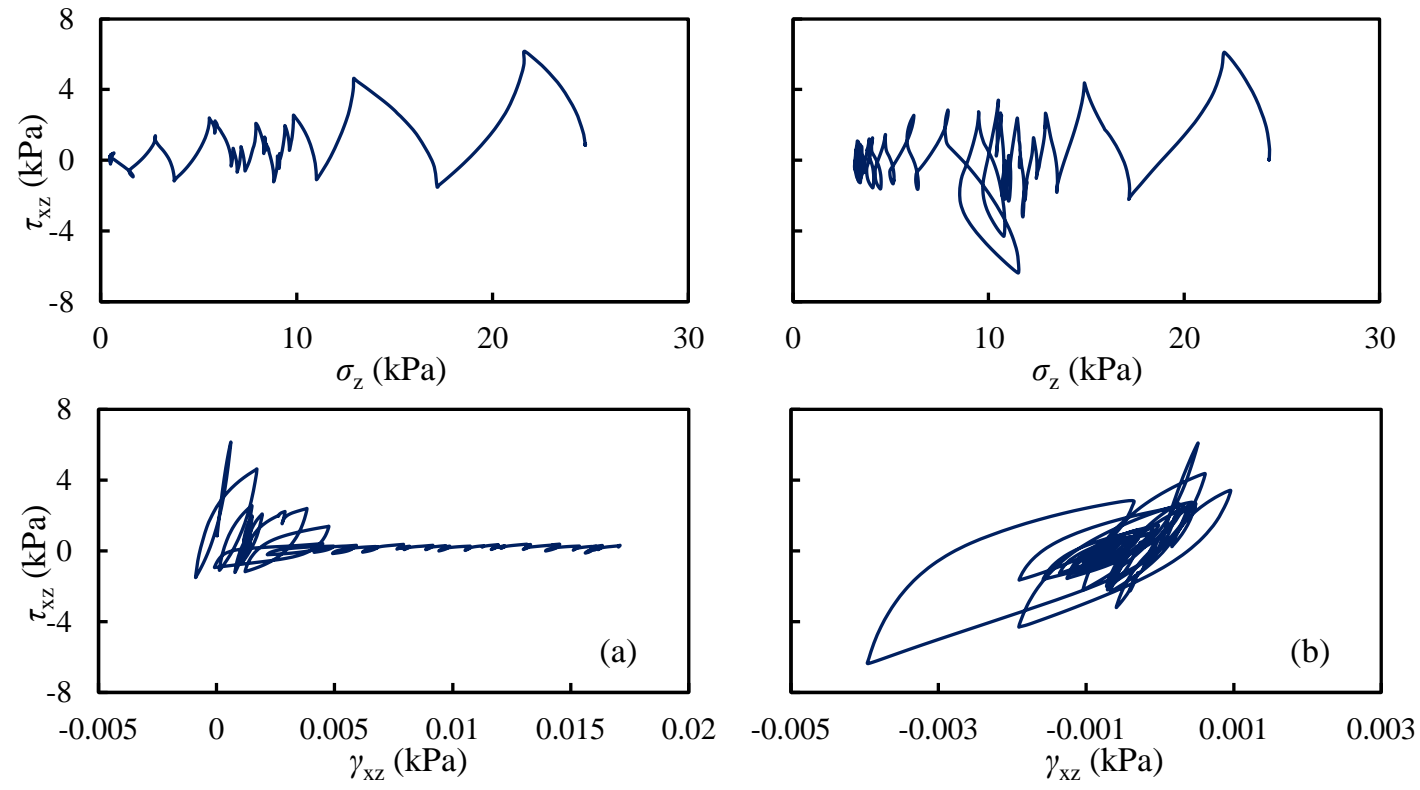

Fig. 10. Simulated stress strain relationship $2.6 \mathrm{~m}$ from ground surface for model ICS: (a) $4.0 \mathrm{~m}$ from pile; (b) $0.2 \mathrm{~m}$ from pile. 


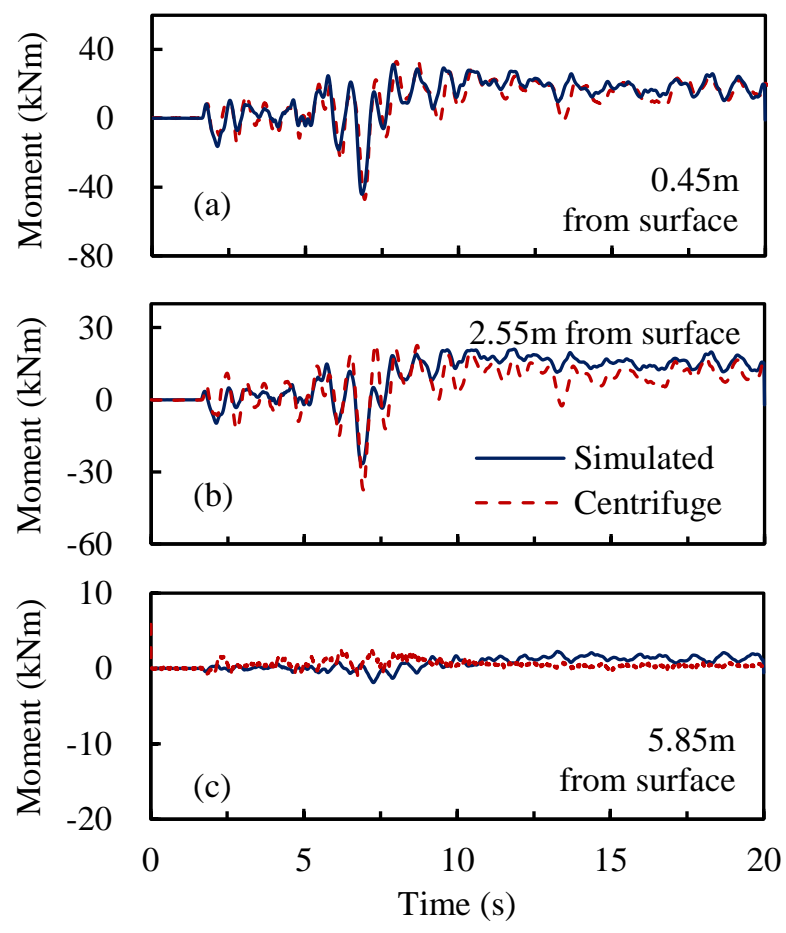

Fig. 11. Pile moment histories at various depths from centrifuge test and numerical simulation on model ICS: (a) at $0.45 \mathrm{~m}$ from ground surface; (b) at $2.55 \mathrm{~m}$ from ground surface; (c) at $5.85 \mathrm{~m}$ from ground surface. 

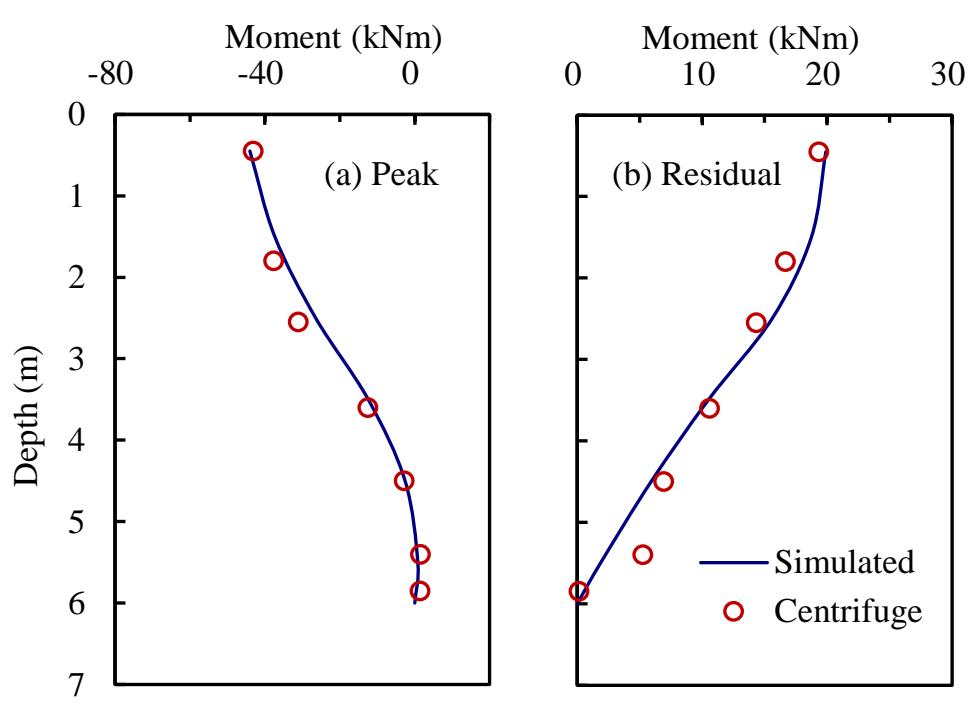

Fig. 12. Two snapshots of the bending moment distribution along the pile in model ICS, taken when peak and maximum residual bending moment occurred. 


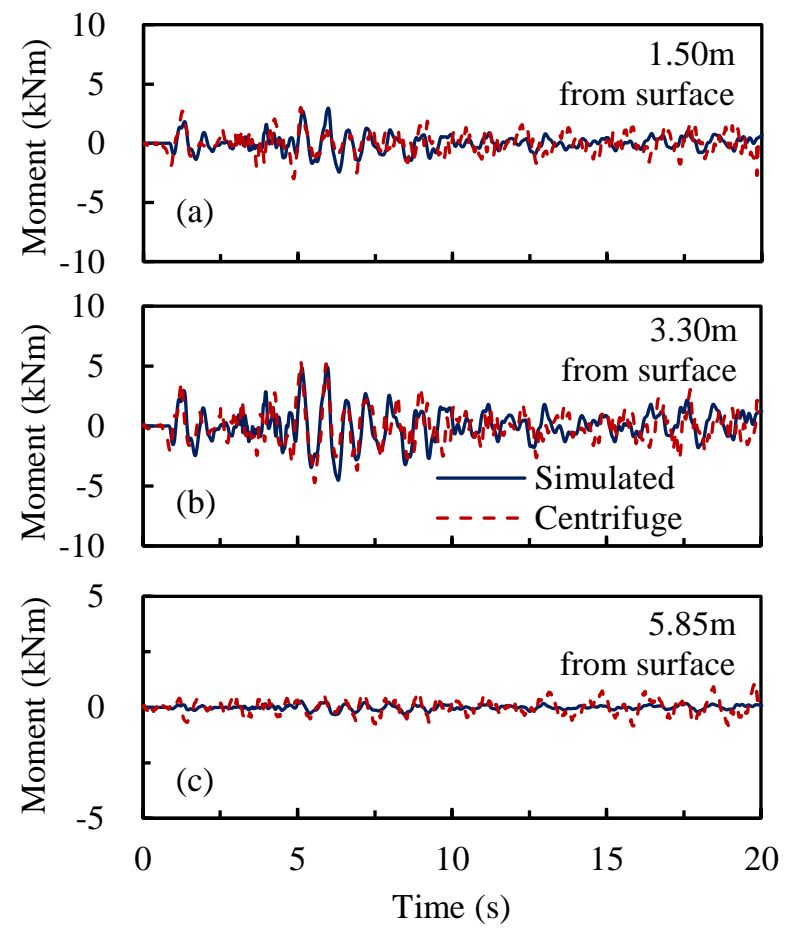

Fig. 13. Pile moment histories at various depths from centrifuge test and numerical simulation on model LNN: (a) at $1.50 \mathrm{~m}$ from ground surface; (b) at $3.30 \mathrm{~m}$ from ground surface; (c) at $5.85 \mathrm{~m}$ from ground surface. 


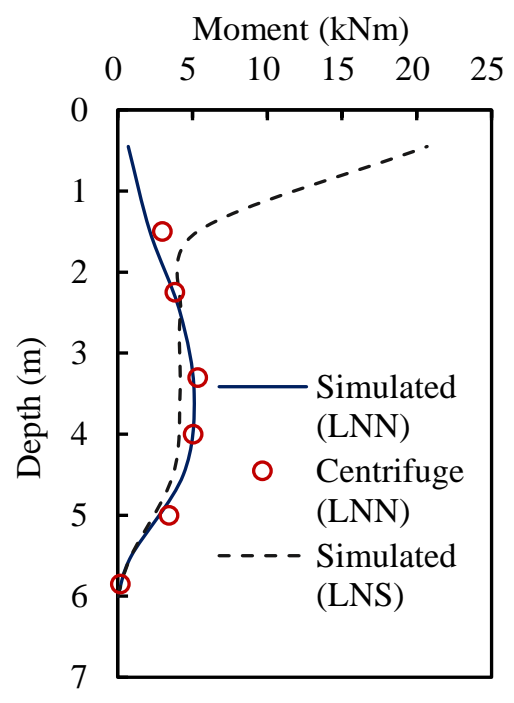

Fig. 14. Two snapshots of the bending moment distribution along the pile in model LNN and LNS respectively (Numerical simulation only for LNS), taken when peak bending moment occurred in each model. 

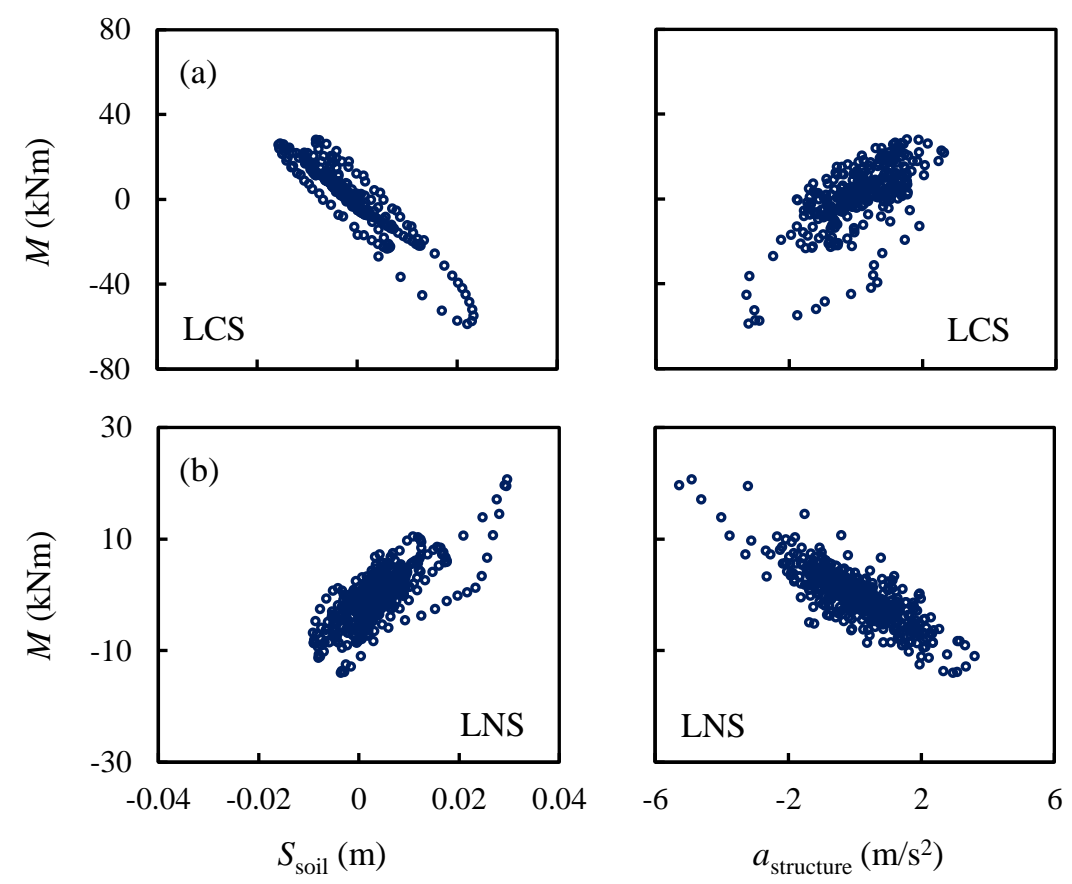

Fig. 15. Relationship between surface soil displacement, structure acceleration and pile moment for: (a) LCS and (b) LNS. 


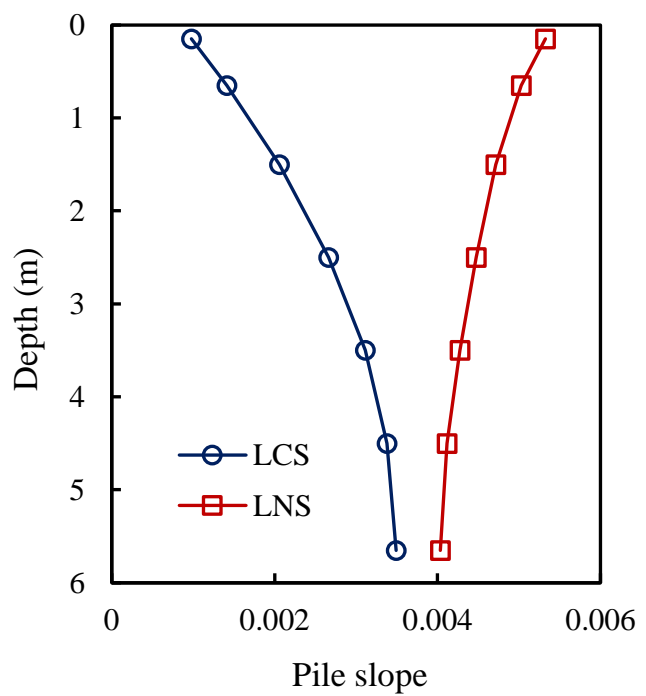

Fig. 16. Pile slope at the time of peak pile moment in model LCS and LNS. 


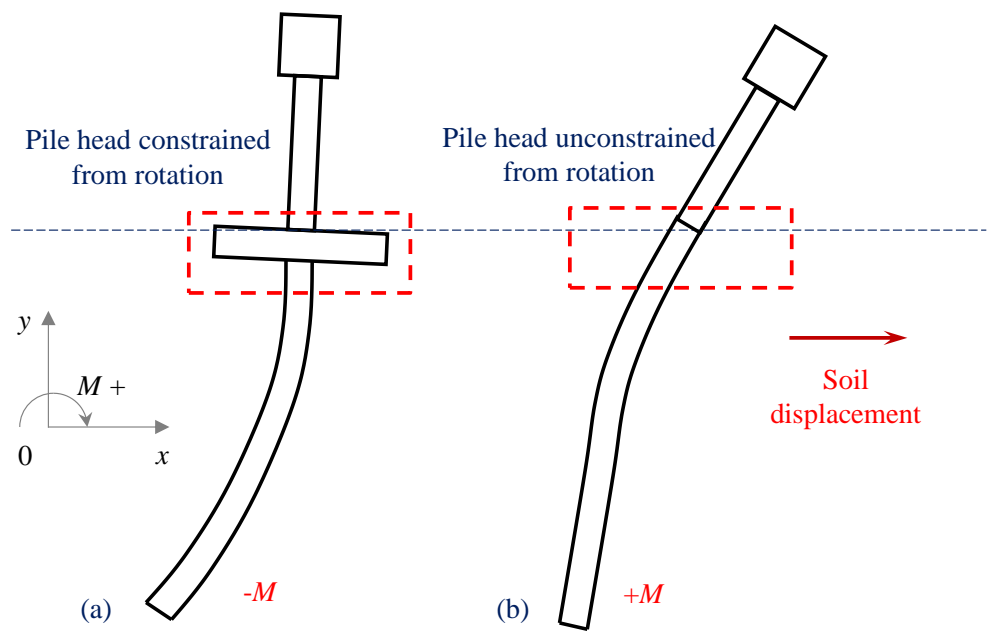

Fig. 17. Effect of pile cap on pile head rotation and pile moment. 

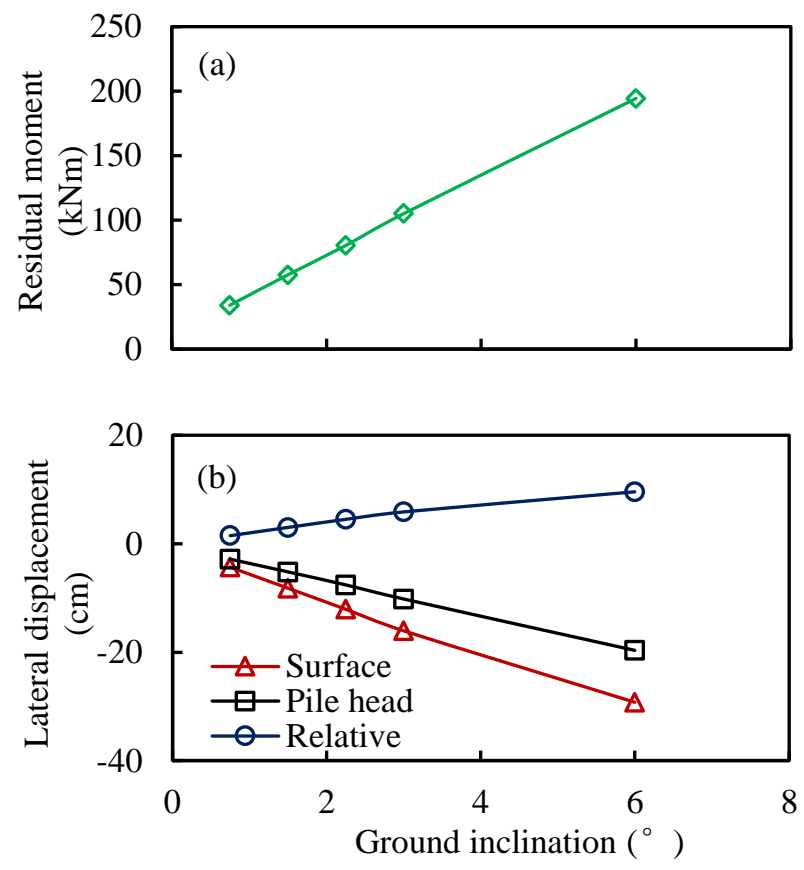

Fig. 18. Effect of ground inclination on residual pile and soil response: (a) residual maximum pile moment; (b) residual soil surface, pile head and pile-soil relative displacement. 


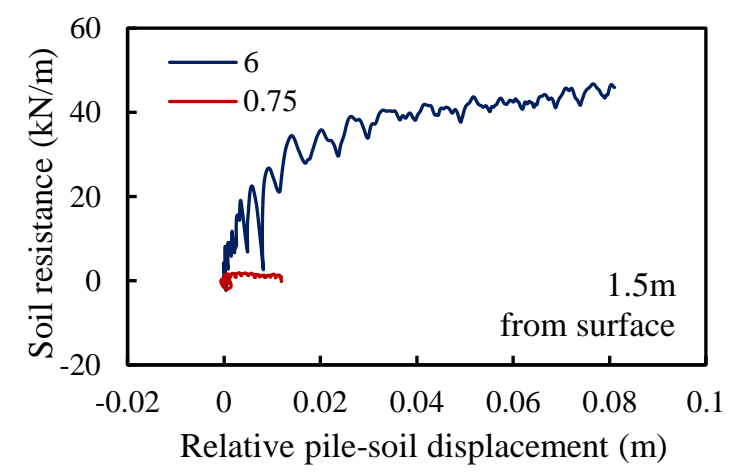

Fig. 19. Back calculated soil resistance $(p-y)$ curve in FEM simulation of models ICS and $\mathrm{ICS}_{5}$. 


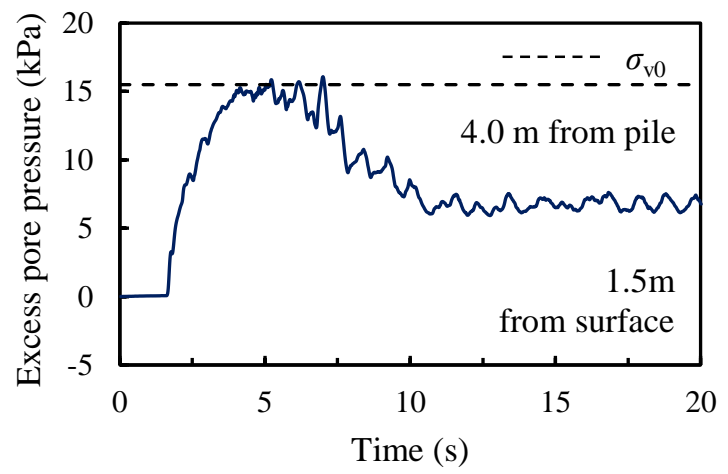

Fig. 20. Simulated excess pore pressure time history of model ICS5. 

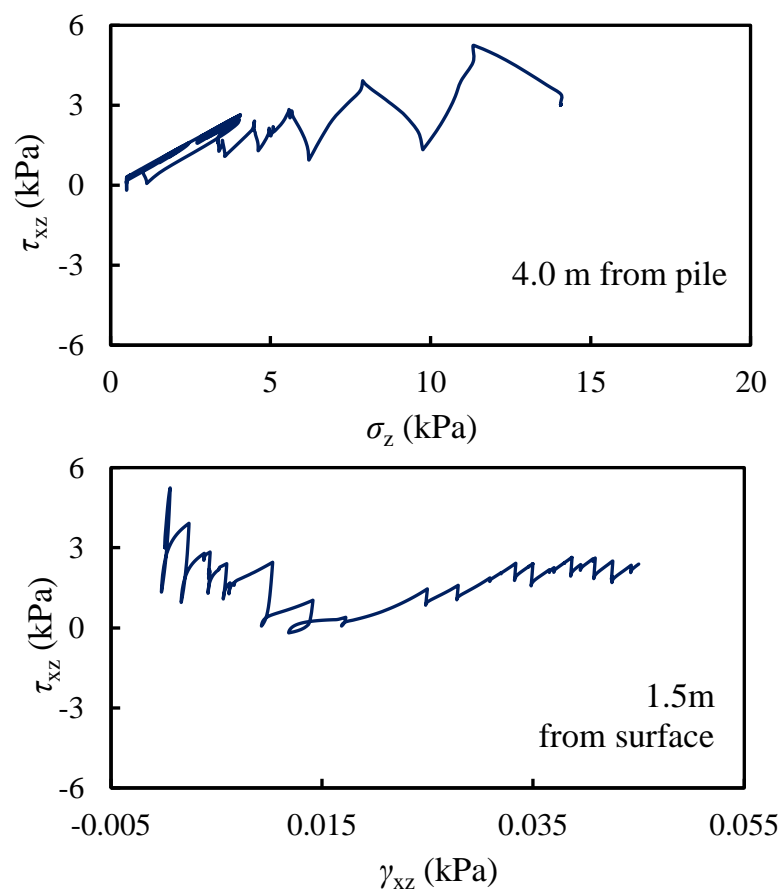

Fig. 21. Simulated stress strain relationship $1.5 \mathrm{~m}$ from ground surface and $4.0 \mathrm{~m}$ from pile for model ICS5. 


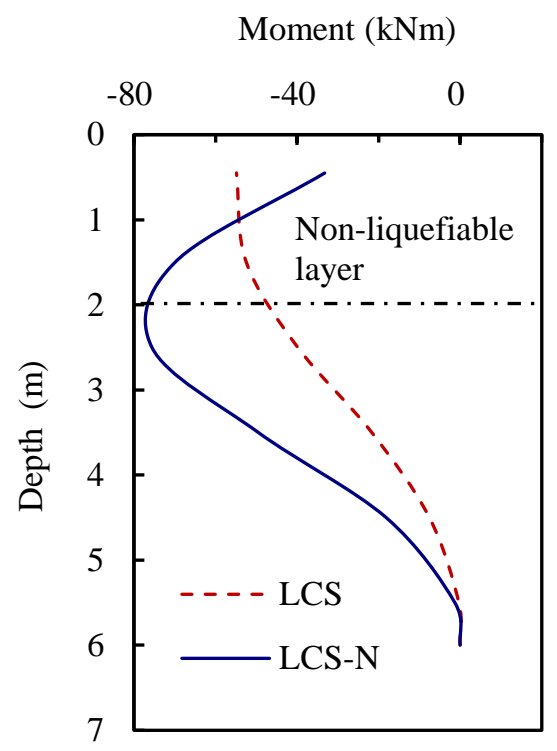

Fig. 22. Comparison between the peak moment distribution of models LCS-N and LCS. 


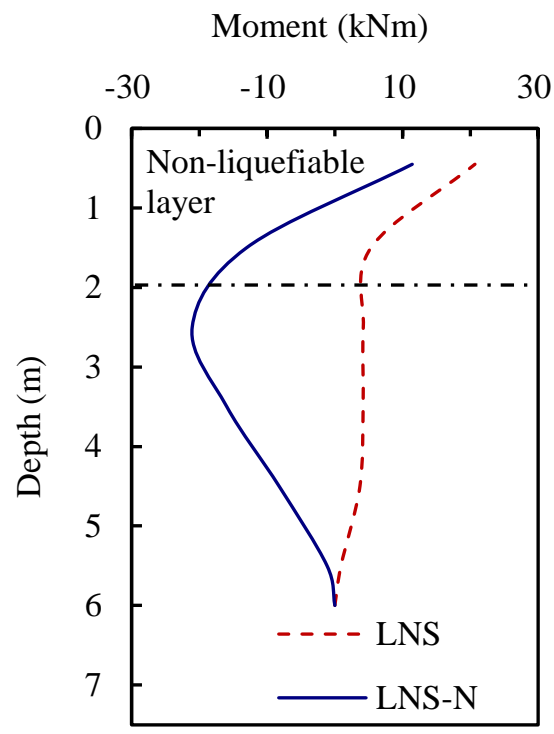

Fig. 23. Comparison between the peak moment distribution of models LNS-N and LNS. 


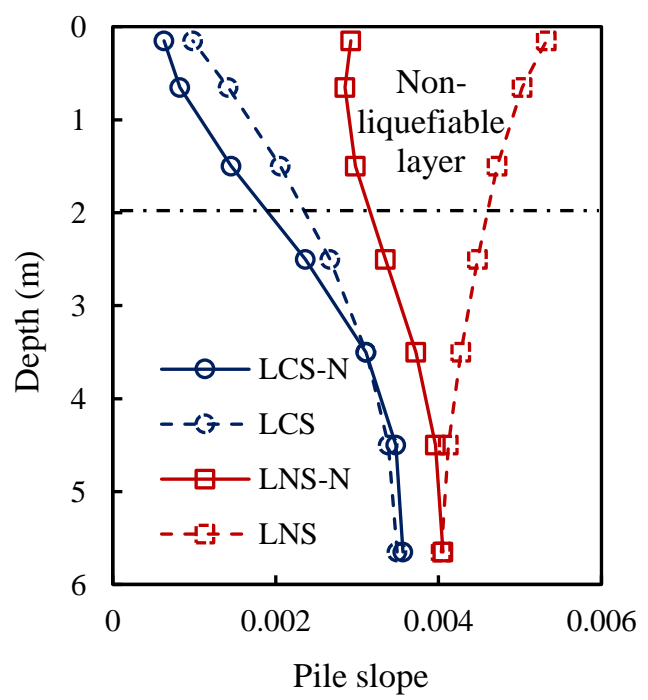

Fig. 24. Effect of non-liquefiable crust on pile head rotation. 
Table 1. Centrifuge test and numerical simulation program

\begin{tabular}{lll}
\hline ID & Ground inclination & Remarks $^{\mathrm{a}}$ \\
\hline LCS & Level & $\mathrm{C}, \mathrm{S}$ \\
ICS & $0.75^{\circ}$ & $\mathrm{C}, \mathrm{S}$ \\
LNN & Level & $\mathrm{C}, \mathrm{S}$ \\
LNS & Level & $\mathrm{S}$ \\
$\mathrm{ICS}_{2}$ & $1.5^{\circ}$ & $\mathrm{S}$ \\
$\mathrm{ICS}_{3}$ & $2.25^{\circ}$ & $\mathrm{S}$ \\
$\mathrm{ICS}_{4}$ & $3^{\mathrm{o}}$ & $\mathrm{S}$ \\
$\mathrm{ICS}_{5}$ & $6^{\mathrm{o}}$ & $\mathrm{S}$ \\
LCS-N & Level & $\mathrm{S}$ \\
LNS-N & Level & $\mathrm{S}$ \\
\hline
\end{tabular}

Note:

a. $\mathrm{C}$ and $\mathrm{S}$ stand for centrifuge test and finite element simulation respectively 
Table 2. Centrifuge shaking table test scale factors

\begin{tabular}{lll}
\hline Quantity & Symbol & Scale factor \\
\hline Length & $l$ & $1 / n$ \\
Density & $\rho$ & 1 \\
Acceleration & $a$ & $n$ \\
Time (Dynamic) & $t_{\mathrm{d}}$ & $1 / n$ \\
Time (Consolidation) & $t_{\mathrm{c}}$ & $1 / n^{2}$ \\
\hline
\end{tabular}

Note: $n$ is the centrifugal acceleration in terms of gravity $(\mathrm{g})$ during the test. 
Table 3. Material parameters used in simulations

\begin{tabular}{|c|c|c|c|}
\hline Fujian sand (CycLiqCPSP) & Value & Interface (Clough-Duncan) & Value \\
\hline$G_{o}$ & 200 & $G_{o c}$ & 500 \\
\hline$\kappa$ & 0.006 & $n$ & 0.52 \\
\hline$h$ & 1.7 & $\phi$ & $30^{\circ}$ \\
\hline$M$ & 1.3 & $R_{f}$ & 0.65 \\
\hline$d_{r e, 1}$ & 0.45 & & \\
\hline$d_{r e, 2}$ & 30 & & \\
\hline$d_{i r}$ & 0.6 & Pile and cap (Elastic) & Value \\
\hline$\alpha$ & 40 & $E$ & $70 \mathrm{GPa}$ \\
\hline$\gamma_{d, r}$ & 0.05 & $v$ & 0.33 \\
\hline$n^{p}$ & 1.1 & & \\
\hline$n^{d}$ & 8 & & \\
\hline$\lambda_{c}$ & 0.023 & Structure column (Elastic) & Value \\
\hline$e_{0}$ & 0.837 & $E$ & $200 \mathrm{GPa}$ \\
\hline$\xi$ & 0.7 & $v$ & 0.3 \\
\hline
\end{tabular}

